\title{
A Case Study on Soil Improvement with Rapid Impact Compaction (RIC)
}

\author{
Emmanouil Spyropoulos, Bassim A. Nawaz, Saleh A. Wohaibi \\ Geotechnical Specialist, Saudi Aramco, Dhahran, Kingdom of Saudi Arabia \\ Email: emmanouil.spyropoulos@aramco.com, bassim.nawaz@aramco.com, saleh.wohaibi@aramco.com
}

How to cite this paper: Spyropoulos, E. Nawaz, B.A. and Wohaibi, S.A. (2020) A Case Study on Soil Improvement with Rapid Impact Compaction (RIC). World Journal of Engineering and Technology, 8, 565-589. https://doi.org/10.4236/wjet.2020.84040

Received: August 17, 2020

Accepted: September 5, 2020

Published: September 8, 2020

Copyright $\odot 2020$ by author(s) and Scientific Research Publishing Inc. This work is licensed under the Creative Commons Attribution International License (CC BY 4.0).

http://creativecommons.org/licenses/by/4.0/

\section{(c) (i) Open Access}

\begin{abstract}
Soil treatment was utilized on numerous production sites to compact cohesion less formations, having the objective to increase earth characteristics and decrease probable subsidence. Within the last few years, Rapid Impact Compaction (RIC) has increased its attractiveness as a soil treatment method. RIC is an innovative dynamic compaction technique primarily used to compact sandy soils where silt and clay contents are low. This work presents a case study of ground improvement using RIC and its suitability for site preparation earthworks. The RIC technique has been performed in an early site preparation which consists of a cut and fill contract for a mega project in the Kingdom of Saudi Arabia. RIC is a process where loose subsurface soils are improved through compaction with the utilization of successive impact blows from the top surface. This project involves the compaction of the fill materials (with an average thickness of $4 \mathrm{~m}$ ) and loose natural formations (averaging 4 $\mathrm{m}$ in depth). The objective of the soil treatment scheme is to increase the relative density of the soils (both fill and natural) to $85 \%$. The usage of the RIC within the site preparation earthwork applications is possible provided the presence of certain elements-specifically, granular materials and particles finer than number 200 sieve-do not exceed $15 \%$. The RIC method proved to be cost- and time-effective when utilized for filling compaction activities since it compacts considerable soil thicknesses with a single action from the top surface, and can be used as an alternative to the traditional method of compacting fill formations in pre-determined lift thicknesses.
\end{abstract}

\section{Keywords}

Rapid Impact Compaction, RIC, Fill Compaction, Cut and Fill, Relative Density, Compaction, Effective Site Preparation, Cone Penetration Test (CPT) 


\section{Introduction}

Rapid Impact Compactor (RIC) is an innovative dynamic compaction device based on the piling hammer technology used to compact sandy soils where silt and clay contents are low. RIC was developed in early 1990s by British Steel Piling (BSP) in conjunction with the British Military as a means of quickly repairing damaged aircraft runways. RIC bridges the shortcomings amongst the surface roller densification techniques (i.e. roller compaction) and deep compaction methods (i.e. deep dynamic compaction), permitting a middle-deep ground improvement. RIC has been used to treat a range of fills and loose natural subsurface soils of a generally granular nature.

Most studies on RIC have been field investigations. [1] measured the degree and depth of compaction over several trials. Further site assessments were also undertaken by numerous authors ([2]-[8]). RIC is similar to deep dynamic compaction where compaction energy produced by impact energy dissipates in the soil by plastic deformation and viscous damping. Plastic distortion created in the ground formations leads to the densification of the earth ([9] [10]).

All above studies mainly refer to the application of the RIC technique for treating shallow loose cohesion less natural soils to a specified compaction degree that meets the performance criteria. This paper addresses the utilization of the RIC method within filling earthwork activities for the densification of at least $4 \mathrm{~m}$ thick soil lifts on a single run from the top surface having completed a successful pilot and respective analysis. Therefore, main objective of this paper is to study the applicability of RIC as an alternate soil improvement technique to the traditional roller compaction at backfilling operations within the onshore areas.

The achievement of the required specifications criteria by using the RIC methodology is analyzed and further discussed within this paper. The major outcomes of this project will be:

1) Mitigation of the problems barricading the use of RIC within the site preparation earthwork applications due to uncertainties related to the depth of improvement and soil formations applicability.

2) Increased assurance in engaging RIC activities for site preparation schemes.

3) Capitalization on the capabilities acquired by RIC related to the reduction of cost and time.

\section{Rapid Impact Compaction (RIC) Method}

The RIC method uses dynamic energy which is transferred by the hydraulic hammer dropping from a pre-determined height onto a steel patented foot (plate), which is continuously kept in contact with the ground. Specifically, this system uses "controlled impact compaction" of the ground by means of a hydraulic hammer ranging from $7 \mathrm{t}$ to $16 \mathrm{t}$ in weight, dropped from heights between $0.3 \mathrm{~m}$ to $1.2 \mathrm{~m}$, onto a $1.5 \mathrm{~m}$ to $2.5 \mathrm{~m}$ steel patent foot. The entire system is mounted within an excavator for easy maneuver. The points are typically positioned on a grid pattern, the spacing of which is determined not only by the 
subsurface soil formations but also by foundation loading and geometry; generally, this spacing is within the range of $2 \mathrm{~m}$ to $6 \mathrm{~m}$. This procedure is constantly repeated within the same compaction point by rapidly raising and dropping the hammer onto the plate. Drop hits can vary at a rate of 40 to 60 blows per minute. Such energy is transported to the subsurface soils in a safe and efficient manner since the steel foot is in contact with the ground at all times.

The way in which RIC improves the ground is a "top-down" process, as compared to dynamic compaction (DC) which is a "bottom-up" process. A dense plug of earth is developed beneath the compaction print as a result of the initial hammer drops. This plug is further advanced by subsequent blows, resulting with the compaction of the deeper layers. When the compaction foot cannot further penetrate the soil surface, this means that no further deep compaction can be achieved.

The usage of RIC within the site preparation earthwork applications is possible provided the following restrictions:

1) Compacting of granular materials with low silt and clay content.

2) Presence of sandy granular materials.

3) Particles finer than No. 200 sieve do not exceed $15 \%$.

4) Depth of improvement does not exceed $5 \mathrm{~m}$.

This technique is used for increasing the bearing capacity of the soil, minimizing settlements, and reducing the liquefaction potential. Substantial improvement to shallow depths (up to $5 \mathrm{~m}$ ) can be accomplished by the usage of RIC. Depth of improvement with the RIC method is less than the deep compaction methods applicable for same soil nature (e.g. vibro compaction, dynamic compaction) but it still greatly overcomes the depth of improvement achieved through the ordinary surface roller compactors. Cone penetration tests (CPTs) are used for verifying the compliance of project specifications on treated ground between RIC points, considered to be the weakest points.

RIC typically is carried out by numerous compaction phases and passes depending on the project specification criteria as well as the pre-treatment soil formations. RIC procedures are established through trials upon which the optimum compaction parameters are defined.

\section{Site Details}

The Marjan offshore oil field is located northeast of Tanajib in the Arabian Gulf. This program is an integrated development project for oil, associated gas, non-associated gas, and cap gas from the Marjan offshore field. The site under consideration is located approximately $20 \mathrm{~km}$ west of Tanajib, Saudi Arabia. The project site consists of considerable cut and fill activities to reach the final grade level.

A preliminary geotechnical site investigation consisting of 111 boreholes, 54 CPTs, and 84 trial pits was undertaken prior to the contract award on the natural grade levels, having the following objectives: 
- To ascertain the appropriateness of natural soil formations to support the planned facilities, and

- To provide soil design parameters for launching foundation modes and sizes within the preliminary design.

The site campaign revealed that very loose to loose surface deposits overlying medium dense sand are scattered randomly over the entire site area, which has an undulating surface with large elevation differences due to which the site need to be prepared. The awarded early site preparation contractor undertook an additional geotechnical campaign prior to any compaction/filling activities. Results showed the existence of loose sandy formation having an average thickness of 3 $\mathrm{m}$ confirming the findings of the preliminary geotechnical campaign, the representative soil profile is presented in Figure 1. The groundwater varied from $4 \mathrm{~m}$ to $15 \mathrm{~m}$ from existing ground levels at the time of the investigation.

As a result, soil improvement measures for treating both the natural and fill formations were required. RIC was the optimal soil mitigation technique as opposed to the traditional roller compaction method, due to the thickness of the loose natural and fill layers, the soil composition, and the time required for the project's completion.

The RIC method is employed in the following cases:

- Below the final grade levels (after excavation/cutting) at cut areas (applicable for $4 \mathrm{~m}$ depth on natural soils).

- Below depression areas (before receiving any fill) at fill areas (applicable for 4 $m$ depth on natural soils).

- At fill formations (applicable for $4 \mathrm{~m}$ thicknesses of fill). Fill thicknesses more than $4 \mathrm{~m}$ are treated in two phases.

The representative soil profiles encountered in conjunction to cut and fill activities are generalized and shown below.

Case 1: Cut Areas Case 2: Fill Areas (0 - 4 m) Case 3: Fill Areas (4 - 8 m)
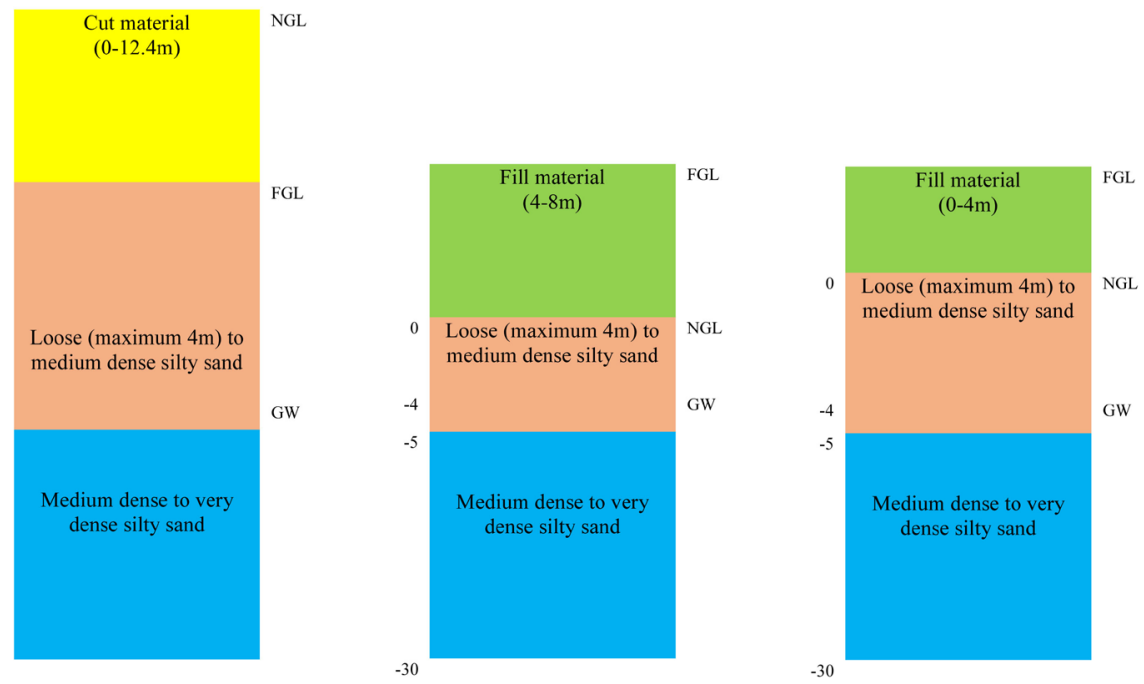

NGL: Natural Ground level, FGL: Final Ground Level, GW: Groundwater

Figure 1. Representative soil conditions. 
The project area includes nearly 6.3 million $\mathrm{m}^{2}$. The site preparation contract consists of cut and fill activities. Cutting operations range from 0 to $12.4 \mathrm{~m}$ (with an average of $6 \mathrm{~m}$ ) while filling thicknesses range from 0 to $8 \mathrm{~m}$ (with an average of $4 \mathrm{~m}$ ). Compaction is required not only on the fill but also on the shallow subsurface's loose natural formations which exist at the following places:

1) Cut Areas ( 3 million $\mathrm{m}^{2}$, which is $47 \%$ of total area): Below the final grade levels (after excavation/cutting) $100 \%$ of the cut areas ( 3 million $\mathrm{m}^{2}$ ) require soil treatment for depths up to $4 \mathrm{~m}$.

2) Fill Areas ( 3.3 million $\mathrm{m}^{2}$, which is $53 \%$ of total area): Below depression areas (before receiving any fill) $100 \%$ of the fill areas $\left(3.3\right.$ million $\mathrm{m}^{2}$ ) require soil treatment for depths up to $4 \mathrm{~m}$.

The objective of the soil treatment scheme is to increase the relative density of both the fill and the loose natural soils to $85 \%$ to meet the project's specified criteria. The tentative grading color plan for cut and fill is shown in Figure 2.
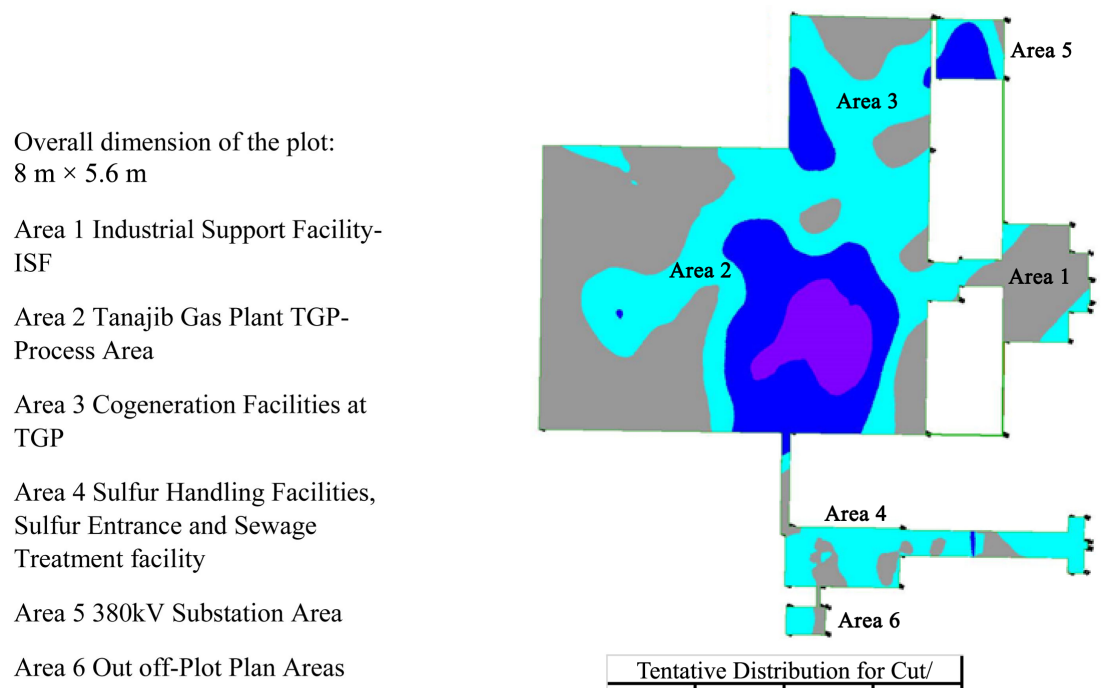

\begin{tabular}{|c|c|c|c|}
\multicolumn{5}{|c|}{ Tentative Distribution for Cut/ } \\
\hline Area & Min & Max & Color \\
\hline Cut & 0 & 12.4 & \\
\hline Fill & 0 & 4 & \\
\hline Fill & 4 & 7.6 & \\
\hline Fill & 4 & 8 & \\
\hline
\end{tabular}

Figure 2. Grading color plan for cut and fill.

The volume of the material (both fill and natural) which underwent compaction procedures equals approximately 41 million $\mathrm{m}^{3}$ (Fill: 15 million $\mathrm{m}^{3}$, Natural: 26 million $\mathrm{m}^{3}$ ).

The RIC method has been recently proposed to provide a sustainable and cost/time alternative to traditional fill compaction activities. Considerable fill thicknesses can be densified in a single lift using RIC as a replacement to the traditional method of compacting fill formations in pre-determined numerous lift thicknesses. The RIC apparatus uses hammer weights with compaction energy ranging from $9 \mathrm{t}$ to $16 \mathrm{t}$ depending on the treatment depth to be achieved. This technique is used to compact loose granular soils (either fill or natural) with thicknesses not exceeding $4 \mathrm{~m}$, with the objective to reinforce its relative density 
and bearing capacity, reduce settlements, and mitigate liquefaction risks.

A quality control program was implemented for both the fill and loose natural soils. This paper provides the elements of design, acceptance criteria, and performance of the implemented soil treatment scheme by means of RIC.

\section{Quality Control and Quality Assurance}

A suitable post-compaction process must be considered for observation and checking. The quality procedure on RIC is comprised of the following steps:

1) Assessment of existing geotechnical information

2) Trial explicit method statements and installation

3) Compaction process

4) Post-treatment geotechnical investigations

5) Receipt of accepted treatment works

\subsection{Pre-RIC Assessment}

A survey of the site should be undertaken before commencing any soil treatment scheme, followed by pre-treatment penetration tests as well as appropriate soil sampling. Depending on the field/lab geotechnical results, the suitable treatment method and parameters (grid spacing, hammer weight, drop height, number of drops, and number of phases/passes, etc.) are assigned through a preliminary soil improvement design which is tested during the treatment trial.

Prior to carrying out any ground improvement in a concerned area, performing the following survey/geotechnical investigations is recommended:

1) Survey of existing ground levels should be initially carried out within the area of concern; without these, no ground improvement can be initiated.

2) Pre-treatment penetration tests, usually CPT, are undertaken in the middle of the corresponding area before beginning any ground treatment developments to determine the nature of the subsoil and the essential improvement method to be utilized.

3) The aforementioned pre-treatment scheme should be supported by undertaking additional exploration boreholes within the weak soil formations.

4) Lab tests on samples retrieved from the exploratory boreholes should include, but will not be limited to, wet sieve analysis/hydrometer, minimum/maximum density, strength, and carbonate content tests.

\subsection{RIC Trials}

For the areas where soil treatment is to be executed, trials are scheduled in consideration to the intended RIC works. Different compaction elements should be tested to define the ideal parameters.

\subsection{RIC Production Works}

Ground improvement by RIC may commence after the trial confirms that the designated practices and procedures are effective and meet the requirements. 
The following should be checked throughout the performance of RIC production works:

1) Survey and pre-treatment penetration tests should be undertaken to determine pre-compaction soil settings throughout the area of improvement similar to trial area.

2) Performance of RIC with satisfactory parameters elected within the trial should be carried out.

3) Post-treatment penetration tests should be undertaken.

\subsection{Post-RIC Assessment}

Survey and post-treatment geotechnical tests, to determine the initial soil levels/properties.

1) Post treatment quality control tests, including penetration and sometimes plate load tests.

2) CPT, recommended to be taken at frequencies of $1000 \mathrm{~m}^{2}$ of worked surface (unless otherwise provided within the specifications) between two successive compaction prints.

3) Post treatment CPT, undertaken within two weeks after execution of compaction works for comfortably allowing the dissipation of excess pore water pressure.

4) CPT equipment, recommended to have a 20 ton capacity, be self-anchoring, and have a cone diameter of $45 \mathrm{~mm}$ and a penetration velocity of $2 \mathrm{~cm} / \mathrm{sec}$.

5) The development of digital and contour plans of ground settlements/heaves.

6) Supplementary post treatment tests or additional/alternative treatment method(s) based on the aforementioned testing and a subsequent evaluation to determine the necessity.

7) Aforementioned field/laboratory tests, following the corresponding ASTM standards.

\section{Acceptance Criteria}

The acceptance criteria applicable to the RIC operations within this study (trial and main production works) rely on the relative density procedures. A relative density of $85 \%$ was set as a criterion and should be attained for both the fill materials (having a thickness ranging from $0-8 \mathrm{~m}$ ) and the natural soil formations (for depths equal to $4 \mathrm{~m}$ ).

Acceptance criteria are developed by estimating the CPT tip resistance, assuming the required project specification in terms of relative density of $85 \%$. For that reason, numerous equations including both the relative density and cone tip resistance are used, resulting on acceptance criteria of cone tip resistance versus depth applicable for relative density of $85 \%$. The correlations of relative density and CPT tip resistance used are:

$$
D_{r}=\frac{1}{C_{2}} \ln \left(\frac{q_{c}}{C_{0}\left(\sigma_{v 0}^{\prime}\right)^{C_{1}}}\right)
$$




$$
\begin{aligned}
& C_{0}=157, C_{1}=0.55, C_{2}=2.41 \\
& D_{r}=-98+\left(66 * \log _{10} \frac{q_{c}}{\left[\sigma_{v 0}^{\prime}\right]^{0.5}}\right)
\end{aligned}
$$

$D_{r}=$ Relative density in percentage

$q_{c}=$ Cone penetration test tip resistance in $\mathrm{MPa}$

$\sigma_{v 0}^{\prime}=$ Effective vertical stress in $\mathrm{MPa}$

Figure 3 shows cone resistance in MPa vs effective vertical stress in $\mathrm{kPa}$ [13].

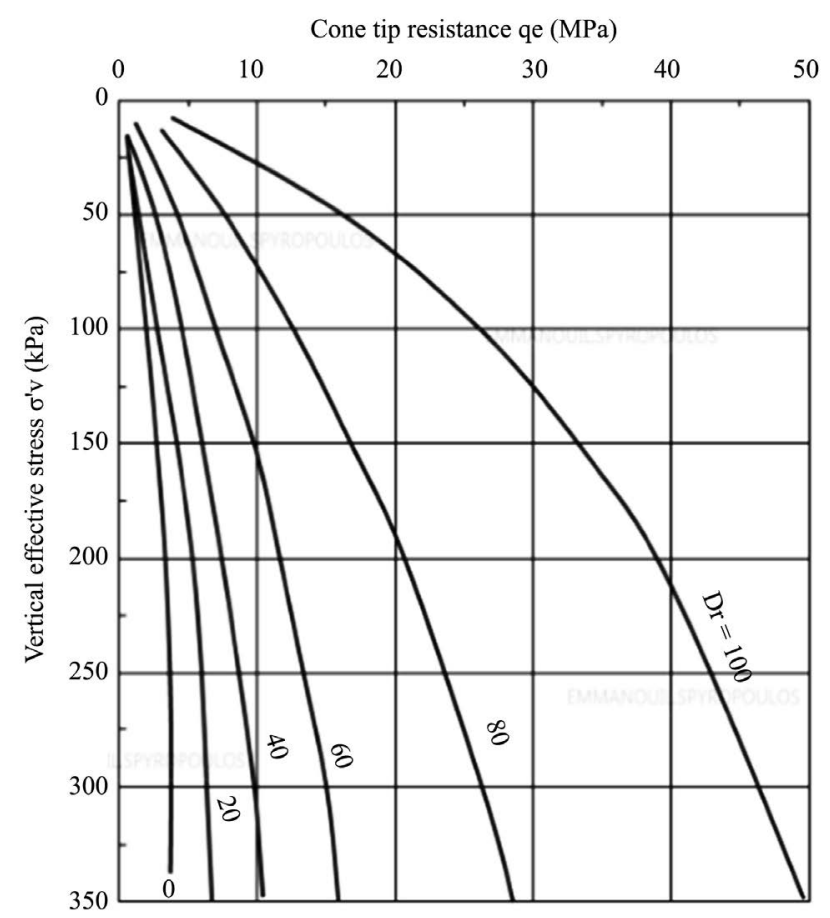

Figure 3. $q_{c}$ vs $\sigma_{v 0}^{\prime}$.

[11] correlation for normally consolidated sands has typically been implemented for the estimation of relative density from CPT $q_{c}$ for assessing engineering performance of the soil post improvement works, as the over consolidated parameters are objectively unreliable.

The weakness in over consolidation estimation and usage is based on the following factors:

1) Multiple correlations from [11] for over consolidated sands showing very deviated results leading to standardization difficulties.

2) Over consolidated samples for studies in calibration chambers were obtained by ground freezing. The primary reason for their additional strength was concluded to be because of cementation/bonding. In the case of compaction-based techniques the bonds are broken (no longer in metastable condition) and subsequently compacted, therefore over consolidation relative density estimations are not compatible for soils improved by Dynamic Compaction, Rapid Impact Compaction, High Energy Impact Compaction. 
The established empirical constants for normally consolidated and overconsolidated sand use Ticino sand, applying index densities. According to this formulation, an estimation of the relative density in normally consolidated sand requires only the knowledge of the vertical effective stress and the cone resistance. Soil constants are in this case given as: $C_{0}=157, C_{1}=0.55, C_{2}=2.41$.

The average acceptance criteria line obtained from the three correlations mentioned above for relative density of $85 \%$ is shown below in Figure 4 .

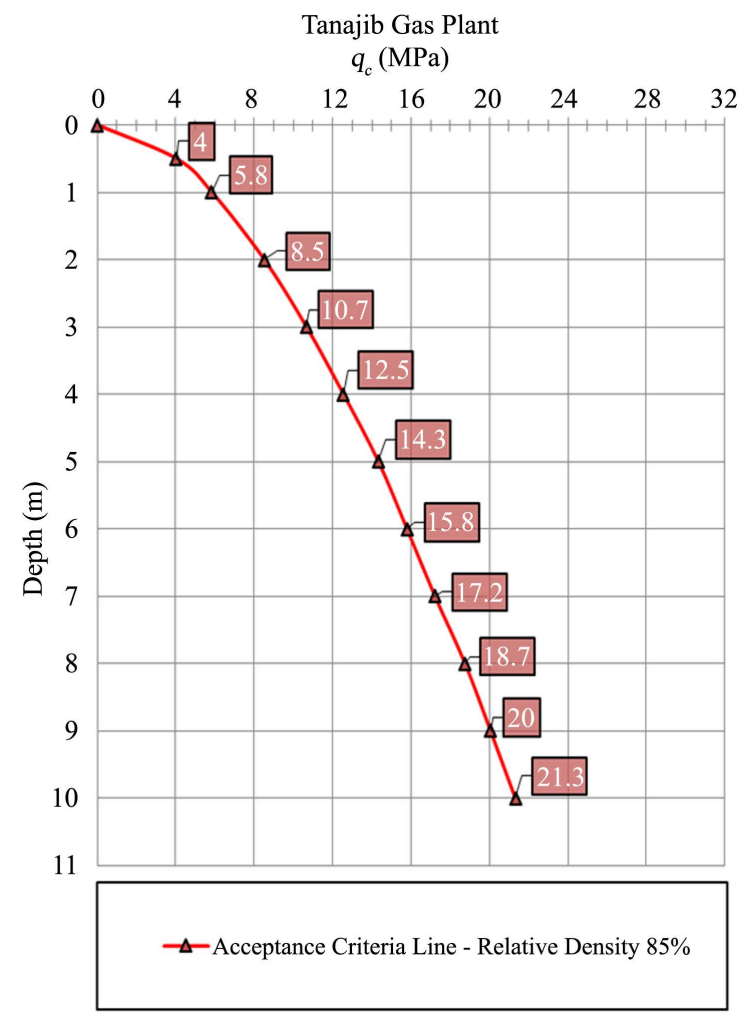

Figure 4. Acceptance criteria line applicable for relative density of $85 \%$.

The post-compaction quality control CPT (undertaken at places in between the RIC points) results are superimposed to the average acceptance criteria graph for ascertaining agreement to the project's specified criteria.

\section{RIC Trials}

RIC trials were carried out to verify the compaction process/compaction design parameters, the suitability of the proposed equipment and accessories, and to confirm the competence of the soil treatment scheme. These trials were executed at the following places for an accurate representation of the soil formations as either natural or fill:

At natural grade level (NGL) for identifying that the compactness of the natural soil deposits of at least $4 \mathrm{~m}$ thickness have achieved the project-specified criteria.

At final grade level (FGL) for ensuring that the strength of the fill materials 


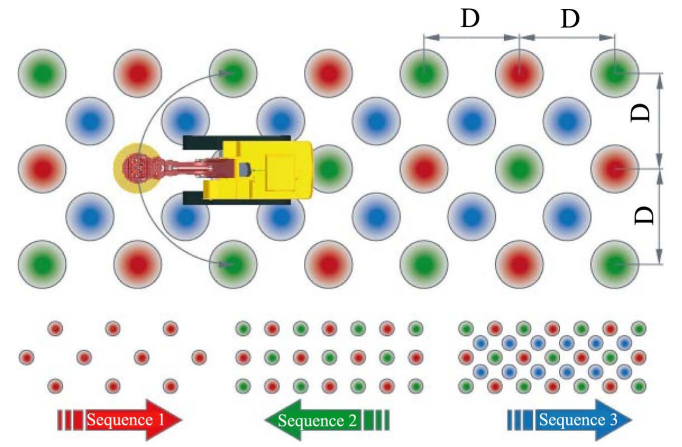

(a)

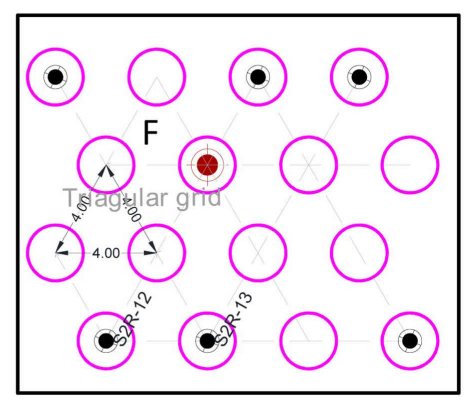

(b)

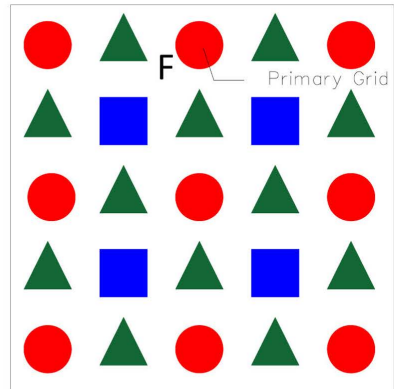

(c)

Figure 5. (a) Various phases of the RIC works highlighted in different colors; (b) Triangular grid pattern points where RIC to be undertaken; (c) Square grid pattern points where RIC to be undertaken. Where: F-Final grid; Red-Primary phase; Blue-Secondary phase; Green-Third phase.

\subsection{Trial NGL}

The performance parameters used for the NGL trial areas were tabulated in below Table 1 and results are shown in Figure 6.

Table 1. Details of trial section on Natural Ground Level (NGL).

\begin{tabular}{cccccc}
\hline \multicolumn{5}{c}{ TS-01 (Final grid: $4.2 \mathrm{~m} \times 4.2 \mathrm{~m}$ ) } \\
\hline Phase & Pass & Hammer Weight & Drop Height & Blows/point & Foot Diameter \\
\hline 1 & 1 & $16 \mathrm{ton}$ & $0.6 \mathrm{~m}$ & 5 & $2.6 \mathrm{~m}$ \\
2 & 1 & $16 \mathrm{ton}$ & $0.6 \mathrm{~m}$ & 5 & $2.6 \mathrm{~m}$ \\
& \multicolumn{5}{c}{ TS-02 (Final Grid: $4.95 \mathrm{~m} \times 4.95 \mathrm{~m}$ ) } \\
Phase & Pass & Hammer Weight & Drop Height & Blows $/$ point & Foot Diameter \\
1 & 1 & 16 ton & $0.6 \mathrm{~m}$ & 5 & $2.6 \mathrm{~m}$ \\
2 & 1 & 16 ton & $0.6 \mathrm{~m}$ & 5 & $2.6 \mathrm{~m}$ \\
\hline
\end{tabular}




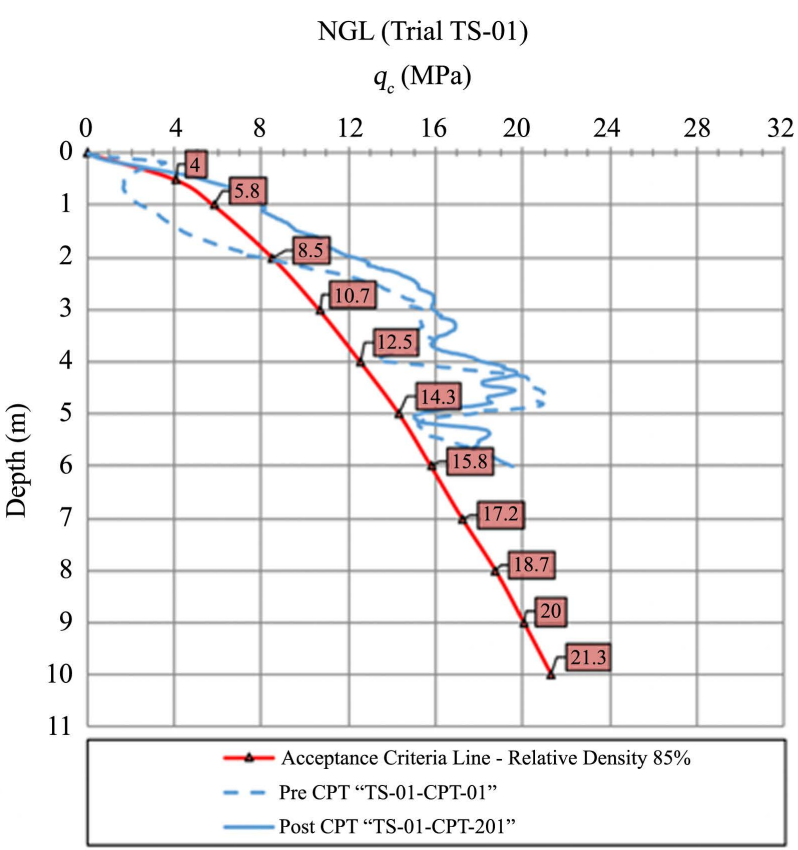

NGL (Trial TS-02)

$q_{\mathrm{c}}(\mathrm{MPa})$

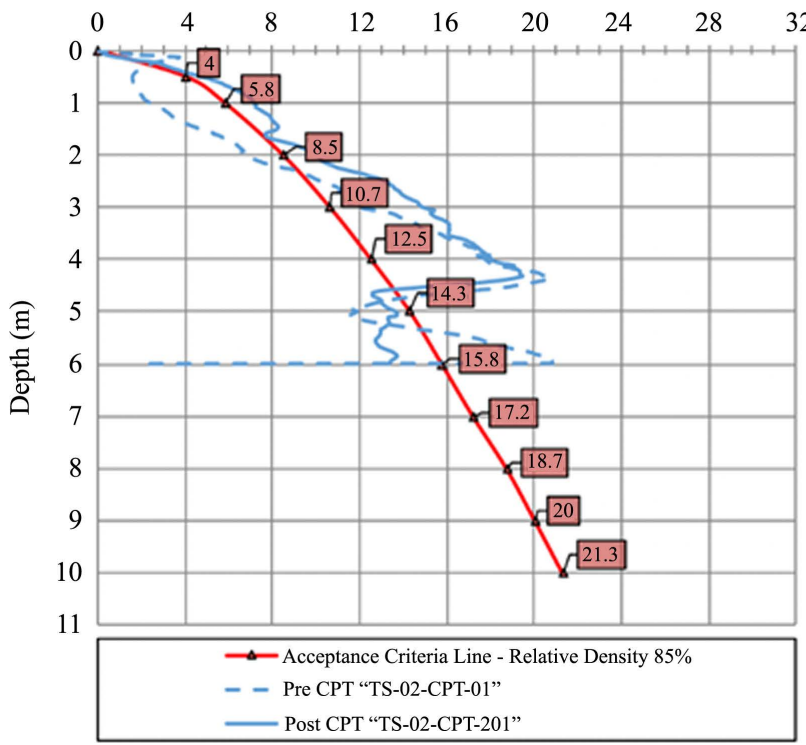

NGL (Trial TS-01)

$q_{\mathrm{c}}(\mathrm{MPa})$

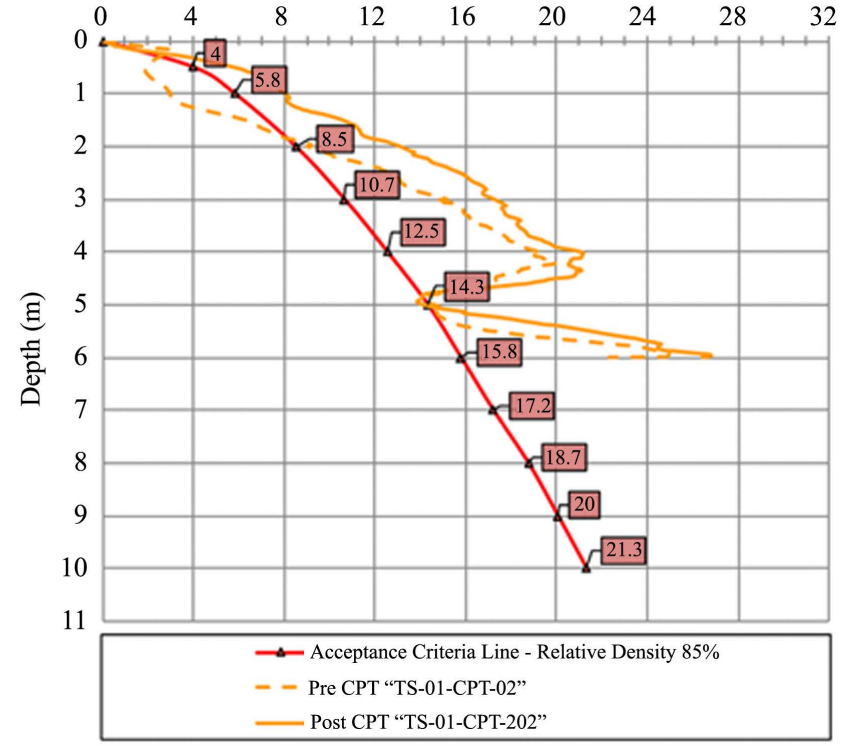

NGL (Trial TS-02)

$q_{c}(\mathrm{MPa})$

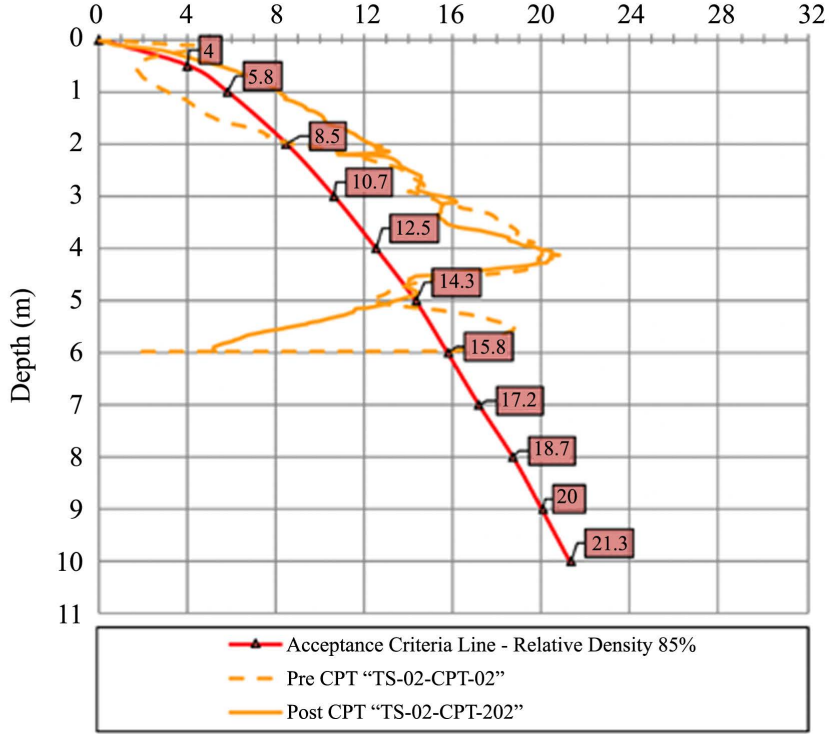

Figure 6. Comparison of pre- and post-CPTs in relation to the acceptance criteria line for the NGL trial.

\subsection{Trial Fill}

The performance parameters used for the fill trial areas were tabulated below in Table 2 and results are shown in Figure 7.

Following the soil improvement works by means of RIC, post CPTs were carried out to evaluate the increase in cone tip resistance with depth as well as to confirm whether the project compaction tolerances were achieved.

The results of the trials corresponding to the natural grade levels shown in Figure 6 revealed the following: 
Fill (Trial Pre \& Post CPTs)

$q_{c}(\mathrm{MPa})$

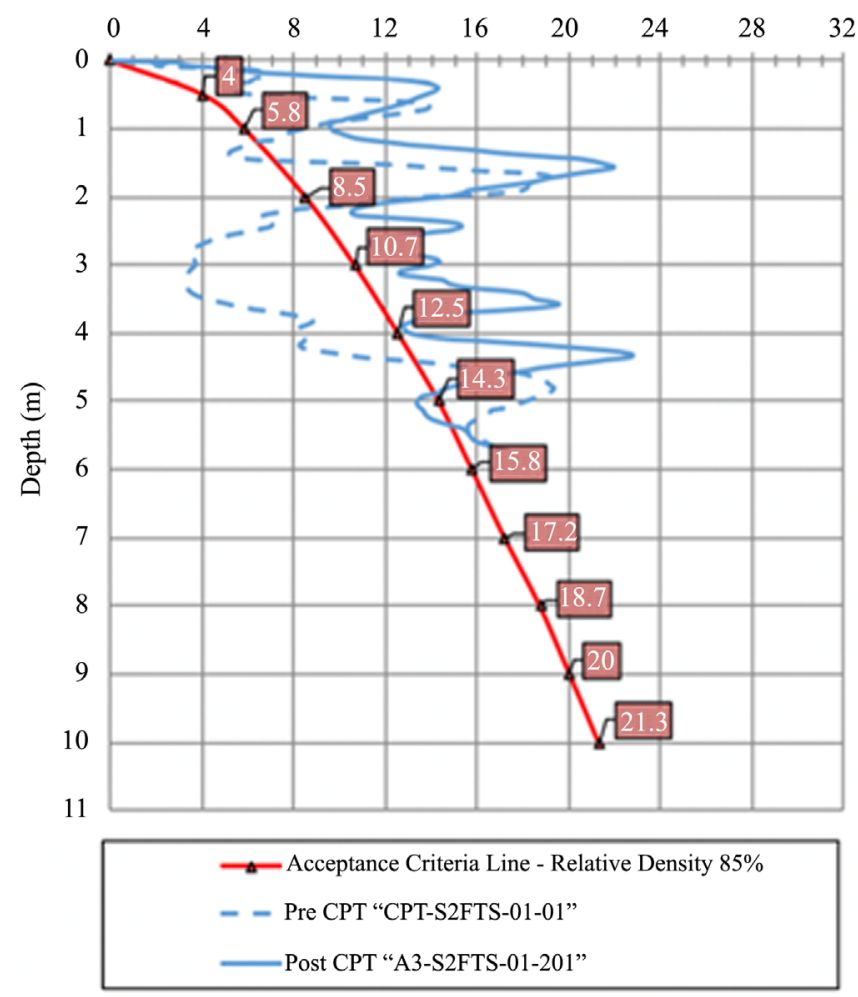

Fill (Trial Pre \& Post CPTs)

$q_{c}(\mathrm{MPa})$

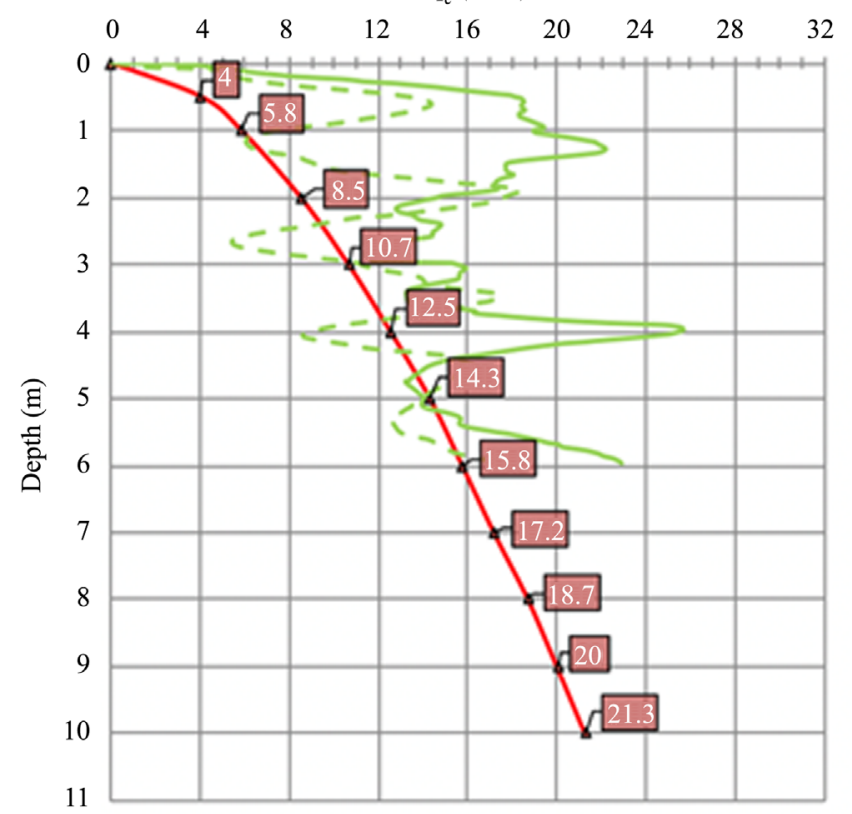

$\longrightarrow$ - Acceptance Criteria Line - Relative Density $85 \%$

- - Pre CPT "CPT-S2FTS-01-03"

- Post CPT "A3-S2FTS-01-203"
Fill (Trial Pre \& Post CPTs)

$q_{\mathrm{c}}(\mathrm{MPa})$

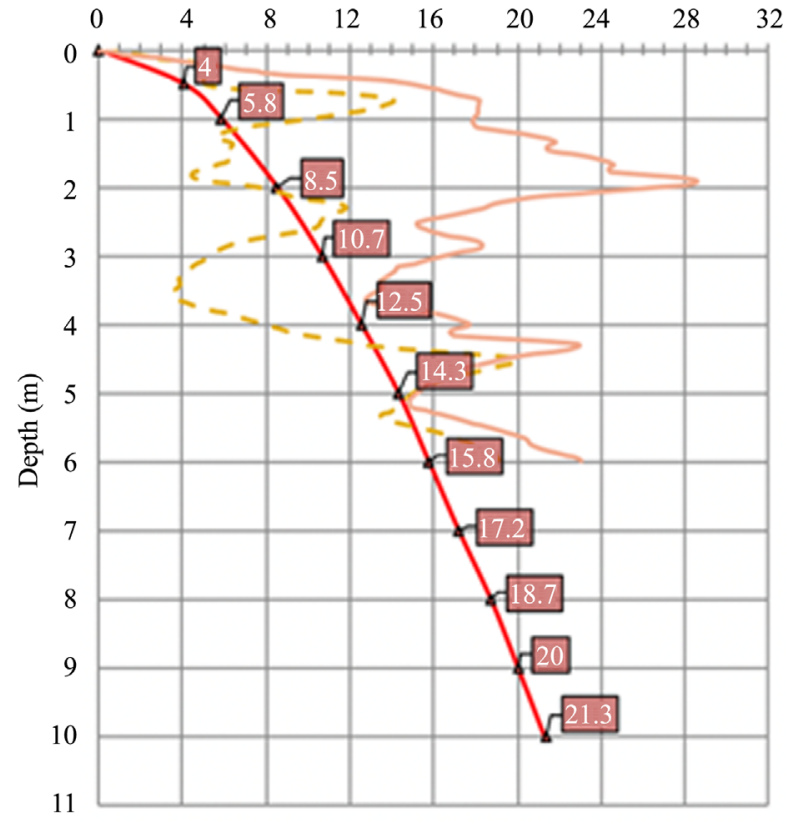

$\triangle$ Acceptance Criteria Line - Relative Density $85 \%$

- - Pre CPT "CPT-S2FTS-01-02"

— Post CPT “A3-S2FTS-01-202”

Fill (Trial Pre \& Post CPTs) $q_{\mathrm{c}}(\mathrm{MPa})$

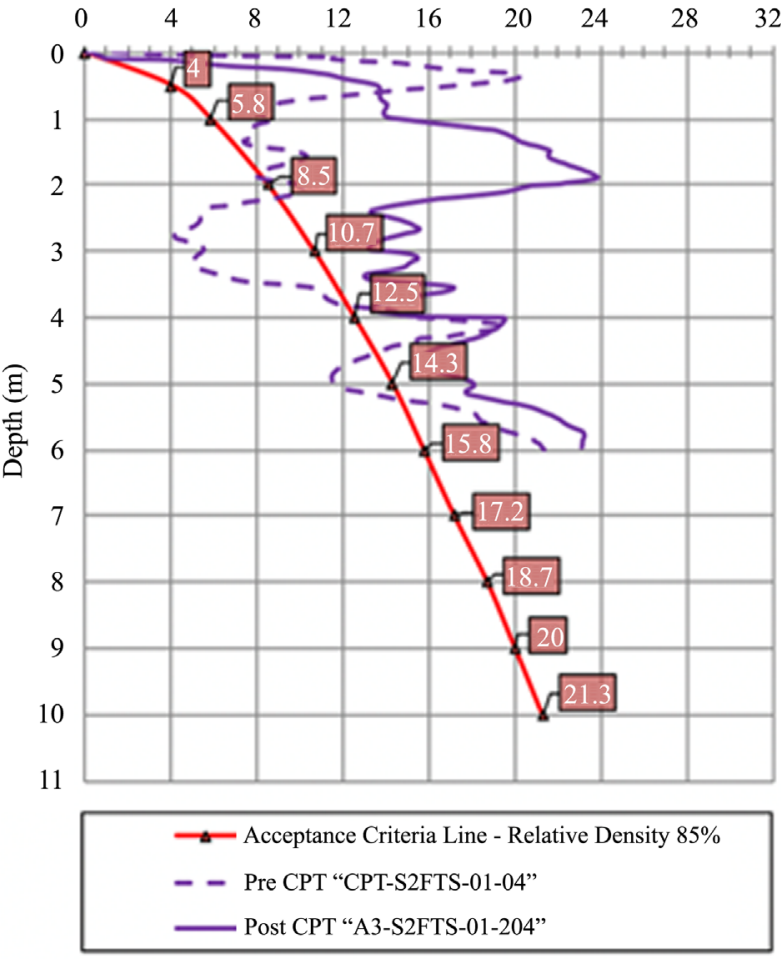

Figure 7. Comparison of pre and post CPTs in relation to the acceptance criteria line for the fill trial. 
Table 2. Details of trial section on fill section.

\begin{tabular}{|c|c|c|c|c|c|}
\hline \multicolumn{6}{|c|}{ Trial Fill } \\
\hline \multicolumn{6}{|c|}{ S2FTS-01 (Final grid: $4 \mathrm{~m}$ triangular)/CPT-S2FTS-01-03 \& A3-S2FTS-01-203 } \\
\hline Phase & Pass & Hammer Weight & Drop Height & Blows/Point & Foot Diameter \\
\hline 1 & 1 & 16 ton & $0.6 \mathrm{~m}$ & 12 & $2.6 \mathrm{~m}$ \\
\hline \multicolumn{6}{|c|}{ S2FTS-02 (Final grid: $4 \times 4$ m)/CPT-S2FTS-01-04 \& A3-S2FTS-01-204 } \\
\hline Phase & Pass & Hammer Weight & Drop Height & Blows/Point & Foot Diameter \\
\hline 1 & 1 & 16 ton & $0.6 \mathrm{~m}$ & 12 & $2.6 \mathrm{~m}$ \\
\hline 2 & 1 & 16 ton & $0.6 \mathrm{~m}$ & 12 & $2.6 \mathrm{~m}$ \\
\hline 3 & 1 & 16 ton & $0.6 \mathrm{~m}$ & 12 & $2.6 \mathrm{~m}$ \\
\hline \multicolumn{6}{|c|}{ S2FTS-03 (Final grid: $2 \times 2$ m)/CPT-S2FTS-01-02 \& A3-S2FTS-01-202 } \\
\hline Phase & Pass & Hammer Weight & Drop Height & Blows/Point & Foot Diameter \\
\hline 1 & 1 & 16 ton & $0.6 \mathrm{~m}$ & 12 & $2.6 \mathrm{~m}$ \\
\hline 2 & 1 & 16 ton & $0.6 \mathrm{~m}$ & 12 & $2.6 \mathrm{~m}$ \\
\hline 3 & 1 & 16 ton & $0.6 \mathrm{~m}$ & 12 & $2.6 \mathrm{~m}$ \\
\hline \multicolumn{6}{|c|}{ S2FTS-04 (Final grid: $3.5 \mathrm{~m}$ triangular)/CPT-S2FTS-01-01 \& A3-S2FTS-01-201 } \\
\hline Phase & Pass & Hammer Weight & Drop Height & Blows/Point & Foot Diameter \\
\hline 1 & 1 & 16 ton & $0.6 \mathrm{~m}$ & 12 & $2.6 \mathrm{~m}$ \\
\hline
\end{tabular}

Post soil treatment findings demonstrate a considerable enhancement of the cone resistance, reaching an increase up to $300 \%$ as compared to results of the tests prior to any compaction.

Post compaction results indicate that a relative density of $85 \%$ was achieved down to depths of $5 \mathrm{~m}$.

The results of the trials corresponding to the fill materials shown in Figure 7 revealed the following:

> Post soil treatment findings demonstrate a considerable enhancement of the cone resistance, reaching an increase of up to $200 \%$ as compared to the results of the tests prior to any compaction.

> Post compaction results indicate that the relative density of $85 \%$ was achieved down to depths of $5 \mathrm{~m}$.

\section{RIC Production}

Having completed the trial schemes at both the natural grade level and fill, the production activities were initiated within the project site using the trial parameters acquired, with adjustments in some cases to fulfill the soil variability at each of the executed grid (subzone, of which each are $1000 \mathrm{~m}^{2}$ in scope). The entire project area was divided into 6300 subzones. 3000 subzones (47\% of the total site area) belong to areas where cut activities were initially carried out to reach the final grade level, followed by RIC compaction of the natural soils. Further- 
more, 3300 subzones (53\% of the site area) correspond to areas of natural soils where the RIC procedures were undertaken at the depression levels prior to any filling in order to achieve the required compaction criteria. Finally, 3300 subzones (53\% of the site area) were assigned to the areas where filling materials have been placed and compacted, having a maximum thickness of $4 \mathrm{~m}$.

A post quality control testing was essential to guarantee that adequate energy was being transmitted to the sub surface formations leading to acceptable performance requirements. Thus, a comparison of the pre and post CPTs was undertaken to evaluate the increment of the soil density after RIC compaction procedures. After completion of RIC activities, a single post CPT per grid box $\left(1000 \mathrm{~m}^{2}\right)$ was performed to evaluate the post compaction performance. The post-compaction CPTs were carried out at places close to the locations of the pre-compaction CPTs at each subzone respectively. We concluded that the post-compaction density generally increases with depth.

Within this subject paper, a number of grid subzones were selected to be analyzed and we were to very whether the project-specified criteria were met. These grid subzones are representative of the soil treatments undertaken at both the areas of the natural sub surface formations (selective areas A1, A2, and A5) and the locations of the fill materials placement (selective areas A1 and A2). Pre- and post-compaction findings are provided in Figures 8-17. Post-compaction results indicate that the relative density of $85 \%$ was comfortably achieved for both the natural (down to depths of $6 \mathrm{~m}$ ) and fill soils.

\subsection{Natural Soils $\left(6,300,000 \mathrm{~m}^{2}\right)$}

\section{Final Grade Levels (After Cut) and Depression Levels (Before Fill)}

The soil improvement RIC performance parameters used for the compaction of the natural soils are provided below in Table 3 .

Table 3. Details of production parameters applied on Natural Ground Level (NGL).

\begin{tabular}{ccccccc}
\hline \multicolumn{6}{c}{ Natural Soils $\left(6,300,000 \mathrm{~m}^{2}\right)$} \\
\hline \multicolumn{7}{c}{ Final Grade Levels (After Cut) and Depression Levels (Before Fill) } \\
\hline \multicolumn{5}{c}{ Type of Grid: Square } \\
\hline Phase & Pass & Hammer Weight & Drop Height & Blows $/$ P & Foot Diameter \\
\hline 1 & 1 & 16 ton & $0.6 \mathrm{~m}$ & 15 & $2.6 \mathrm{~m}$ \\
2 & 1 & 16 ton & $0.6 \mathrm{~m}$ & 15 & $2.6 \mathrm{~m}$ \\
3 & 1 & 16 ton & $0.6 \mathrm{~m}$ & 15 & $2.6 \mathrm{~m}$ \\
\hline
\end{tabular}

The CPTs performed in area A1, A2 and A5 from final grade levels (after cut) and depression levels (before fill) prior and after compaction are shown in Figures 8-14 along with the acceptance criteria. 


\section{Area A1}

NGL

Subzone A1-P1-0233

$q_{\mathrm{c}}(\mathrm{MPa})$

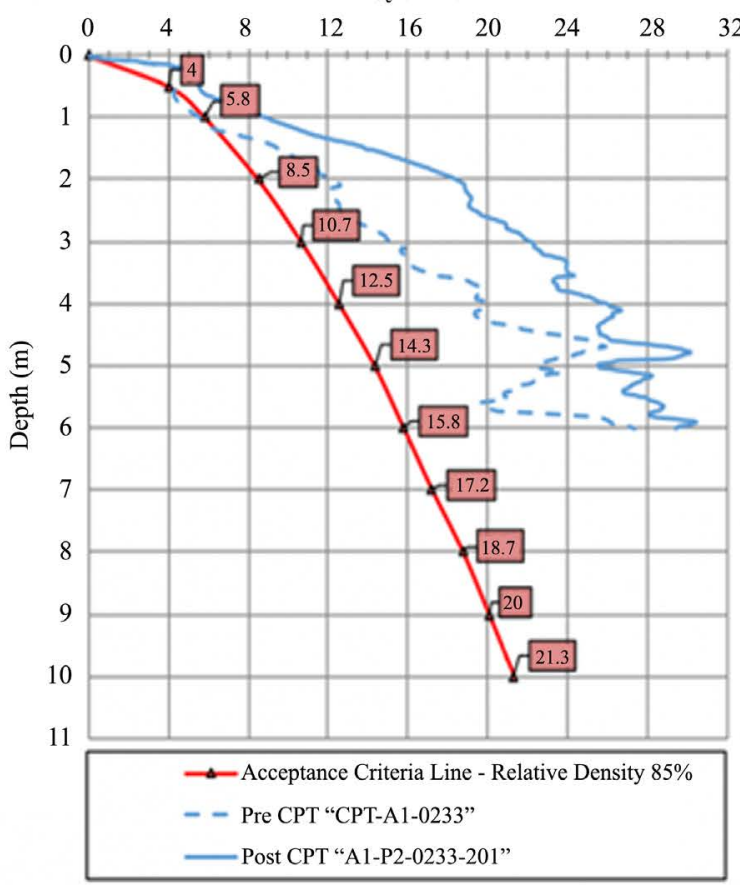

NGL

Subzone A1-P2-0108

$q_{c}(\mathrm{MPa})$

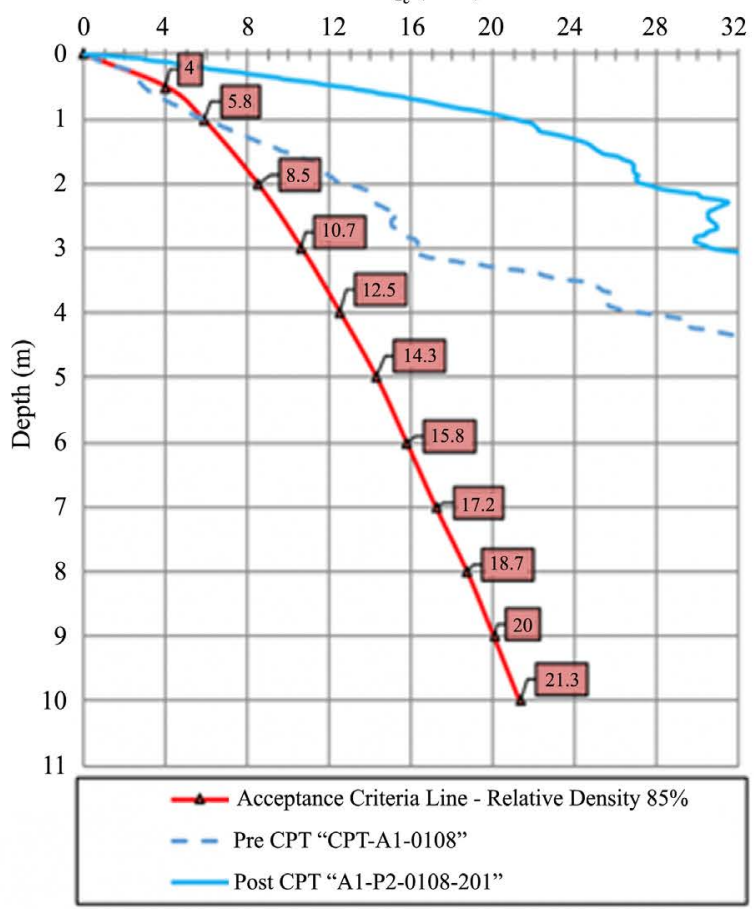

NGL

Subzone A1-P1-0234

$q_{\mathrm{c}}(\mathrm{MPa})$

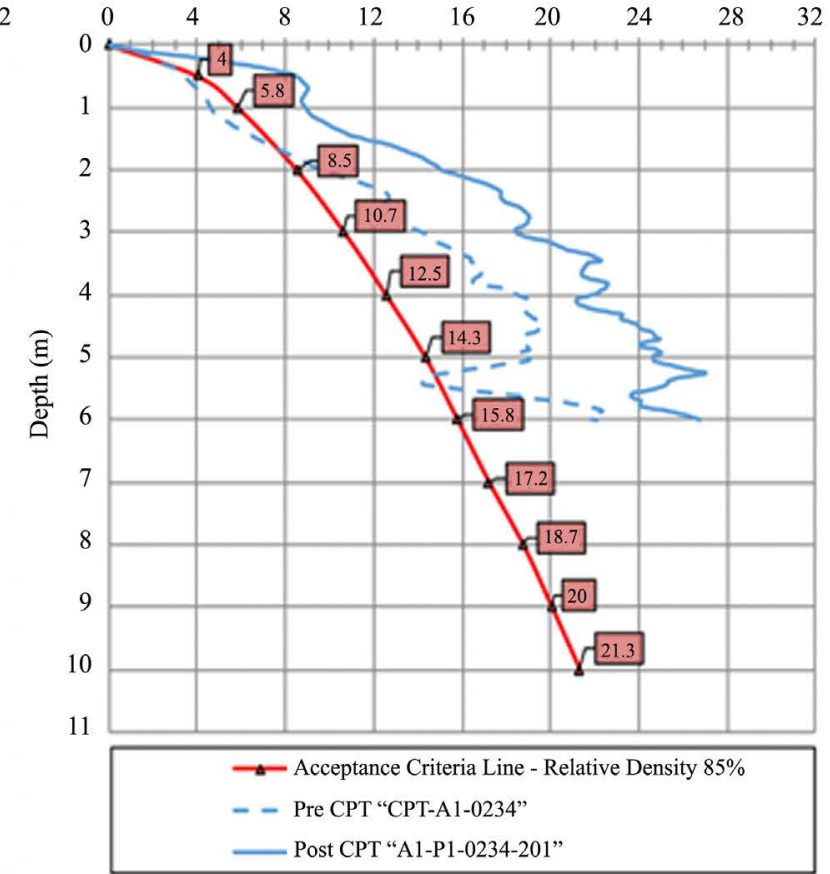

NGL

Subzone A1-P3-0237

$q_{\mathrm{c}}(\mathrm{MPa})$

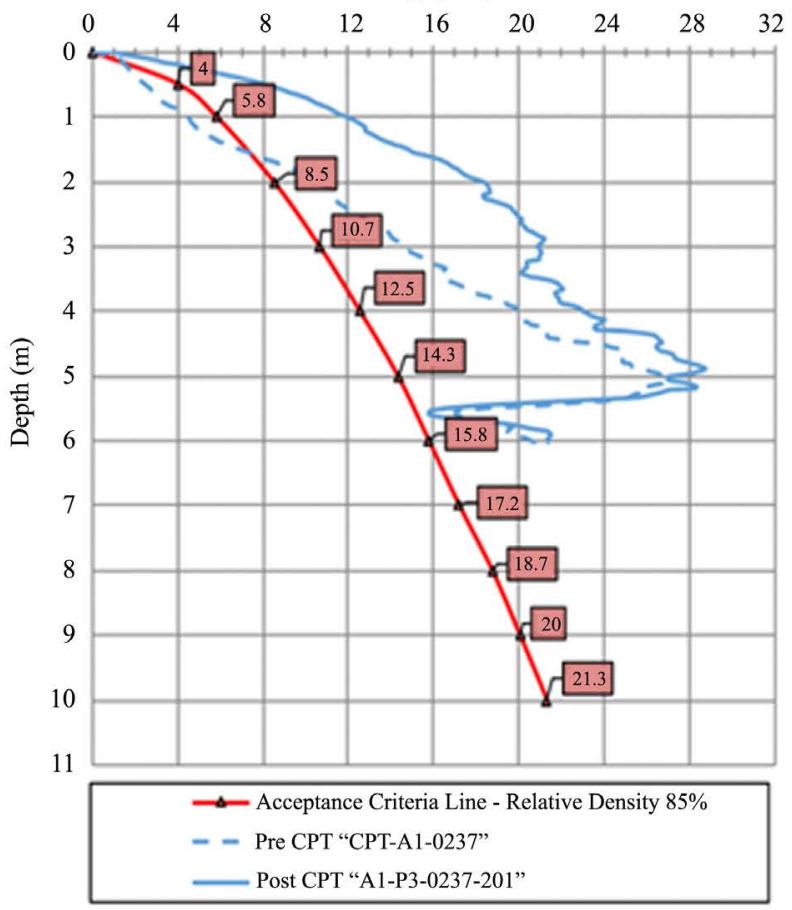

Figure 8. Natural soils, area 1, Subzone P1-0233, P1-0234, P2-0108, P3-0237. 


\section{Area A2}

NGL

Subzone A2-P2-0183

$q_{\mathrm{c}}(\mathrm{MPa})$
NGL

Subzone A2-P2-0491

$q_{c}(\mathrm{MPa})$

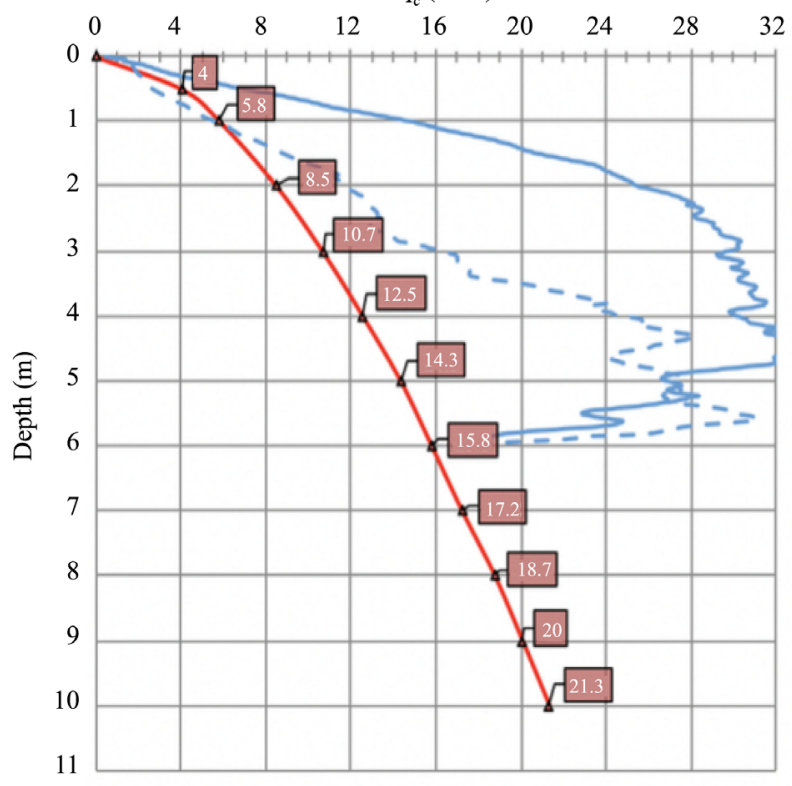

$\triangle$ Acceptance Criteria Line - Relative Density $85 \%$

- - Pre CPT "CPT-A2-0183"

— Post CPT “A2-P2-0183-201”

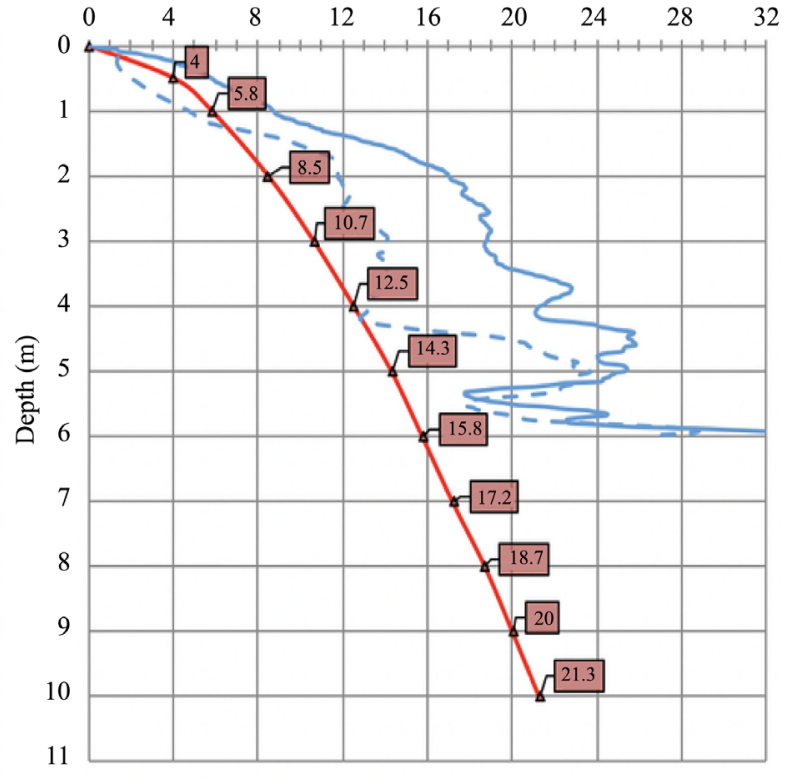

$\triangle$ Acceptance Criteria Line - Relative Density $85 \%$

- - Pre CPT "CPT-A2-0491"

— Post CPT “A2-P2-0491-201”

NGL

Subzone A2-P3-1267

$q_{c}(\mathrm{MPa})$

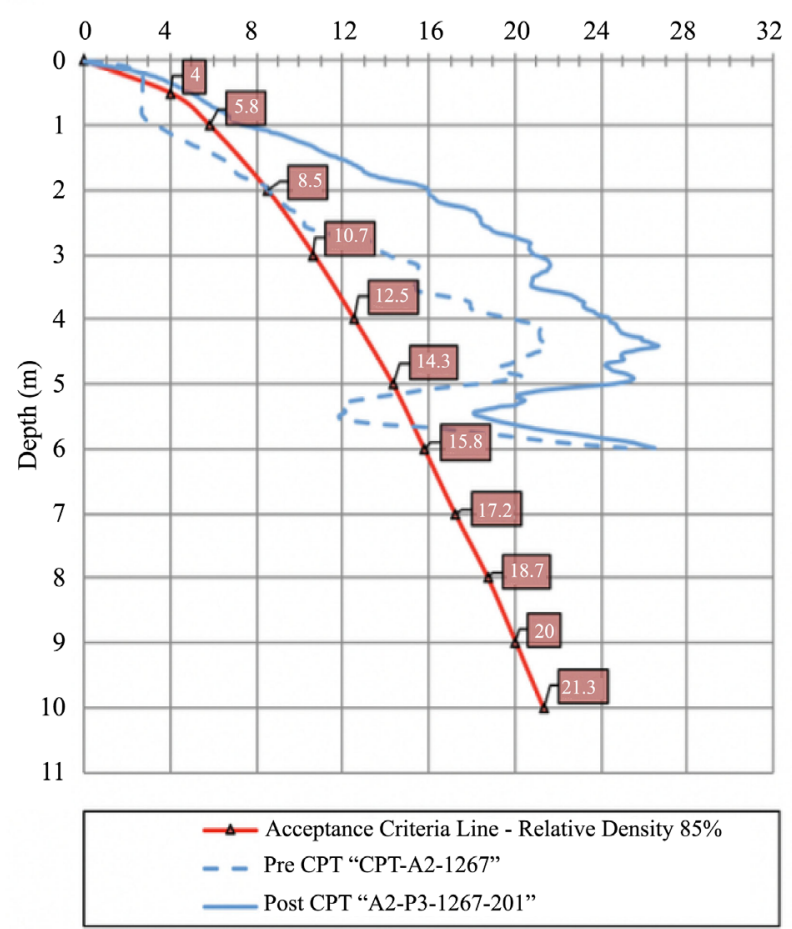

NGL

Subzone A2-P5-2489

$q_{c}(\mathrm{MPa})$

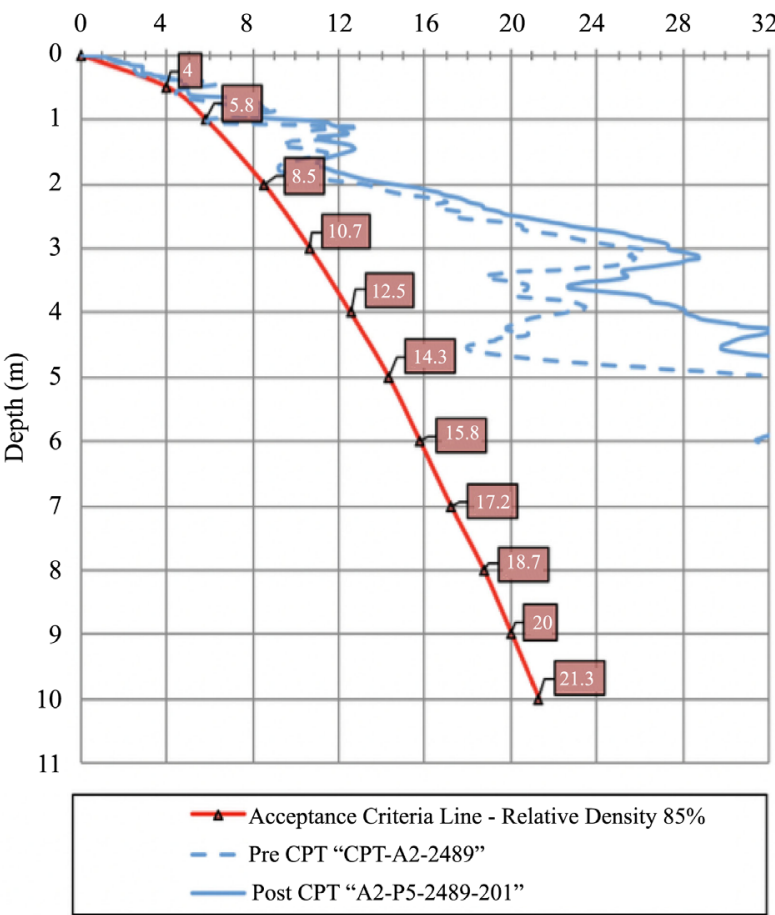

Figure 9. Natural soils, area 2, Subzone P2-0183, P2-0491, P3-1267, P5-2489. 
NGL

Subzone A2-P2-1276

$q_{c}(\mathrm{MPa})$

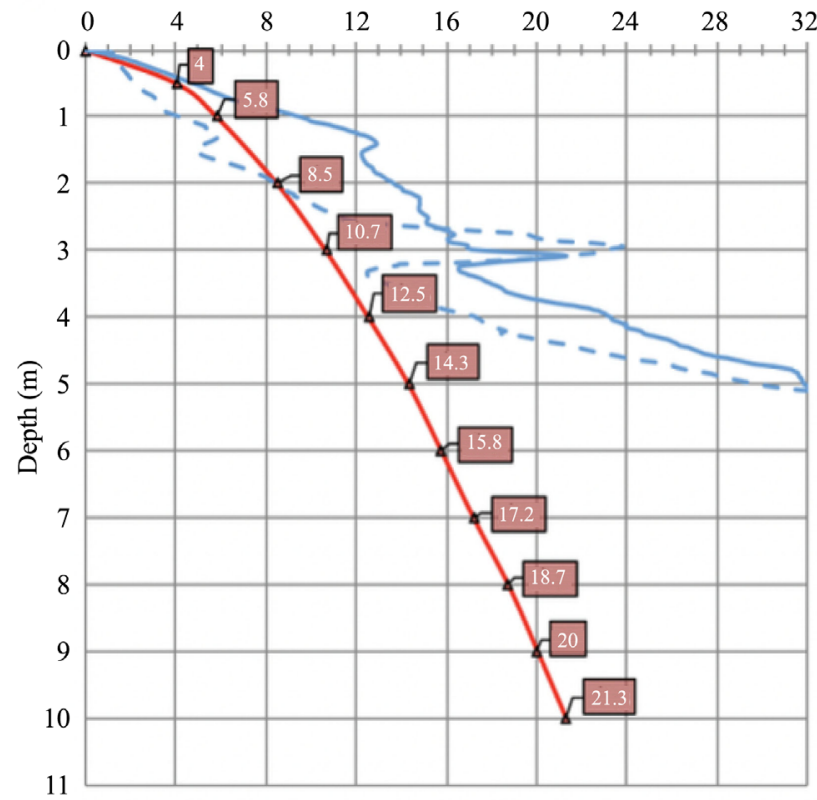

$\triangle$ Acceptance Criteria Line - Relative Density 85\%

- - Pre CPT "CPT-A2-1276"

- Post CPT “A2-P2-1276-201”

NGL

Subzone A2-P5-2751

$q_{\mathrm{c}}(\mathrm{MPa})$

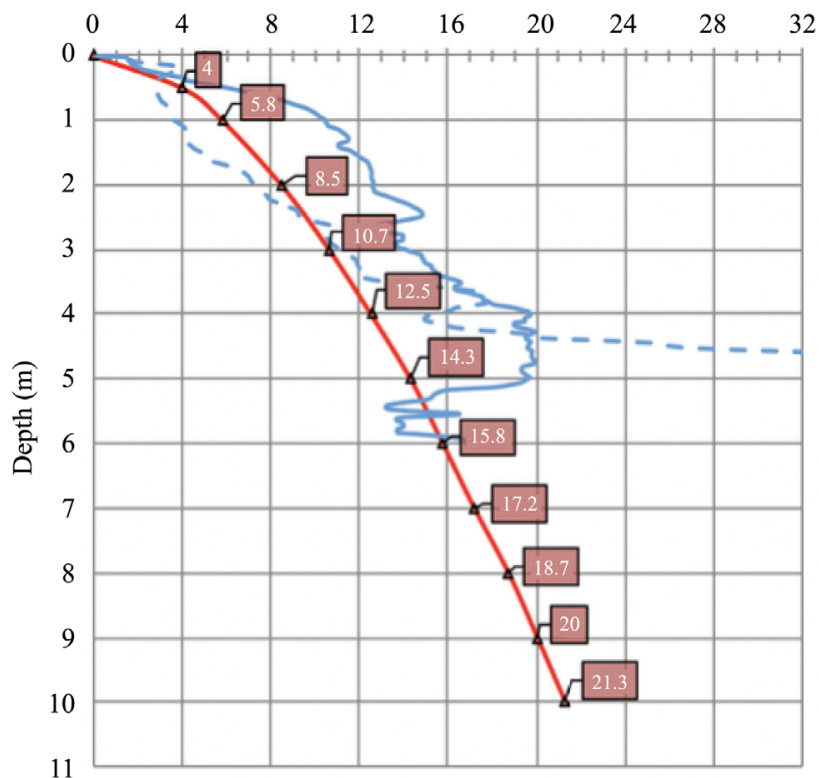

$\multimap$ Acceptance Criteria Line - Relative Density 85\%

- - Pre CPT "CPT-A2-2751"

- Post CPT "A2-P2-2751-201"
NGL

Subzone A2-P2-1337

$q_{\mathrm{c}}(\mathrm{MPa})$

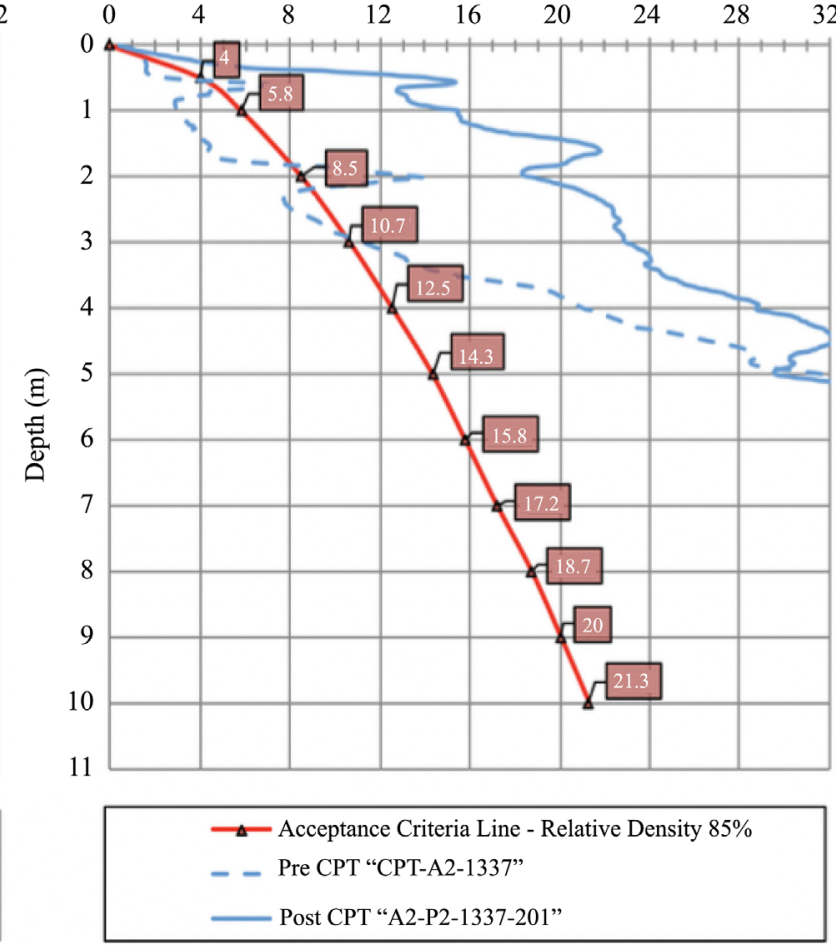

NGL

Subzone A2-P5-2911

$q_{\mathrm{c}}(\mathrm{MPa})$

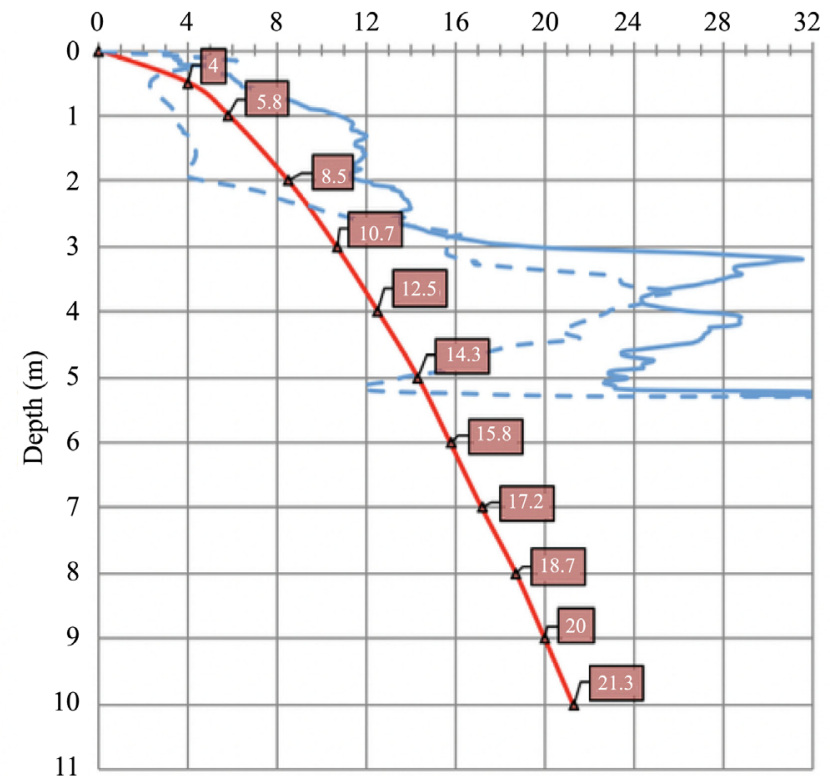

$\checkmark$ Acceptance Criteria Line - Relative Density $85 \%$

- - Pre CPT "CPT-A2-2911"

- Post CPT "A2-P2-2911-201"

Figure 10. Natural soils, area 2, Subzone P3-1276, P3-1337, P5-2751, P5-2911. 
NGL

Subzone A2-P3-0258 $q_{\mathrm{c}}(\mathrm{MPa})$

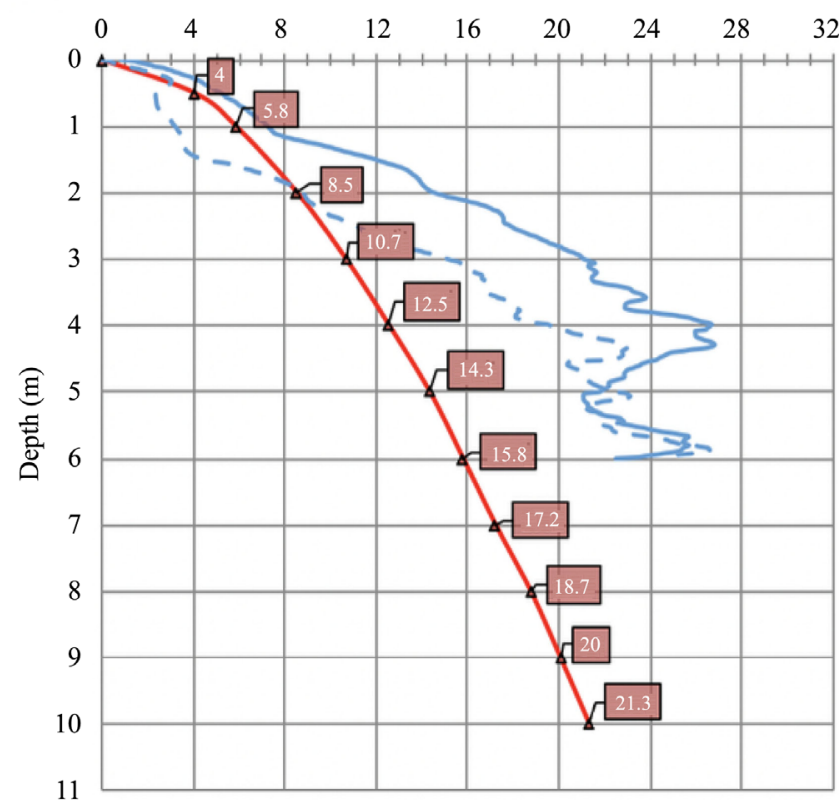

$\triangle-$ Acceptance Criteria Line - Relative Density $85 \%$

- - Pre CPT "CPT-A2-0258"

— Post CPT "A2-P3-0258-201"

NGL

Subzone A2-P6-2227

$q_{\mathrm{c}}(\mathrm{MPa})$

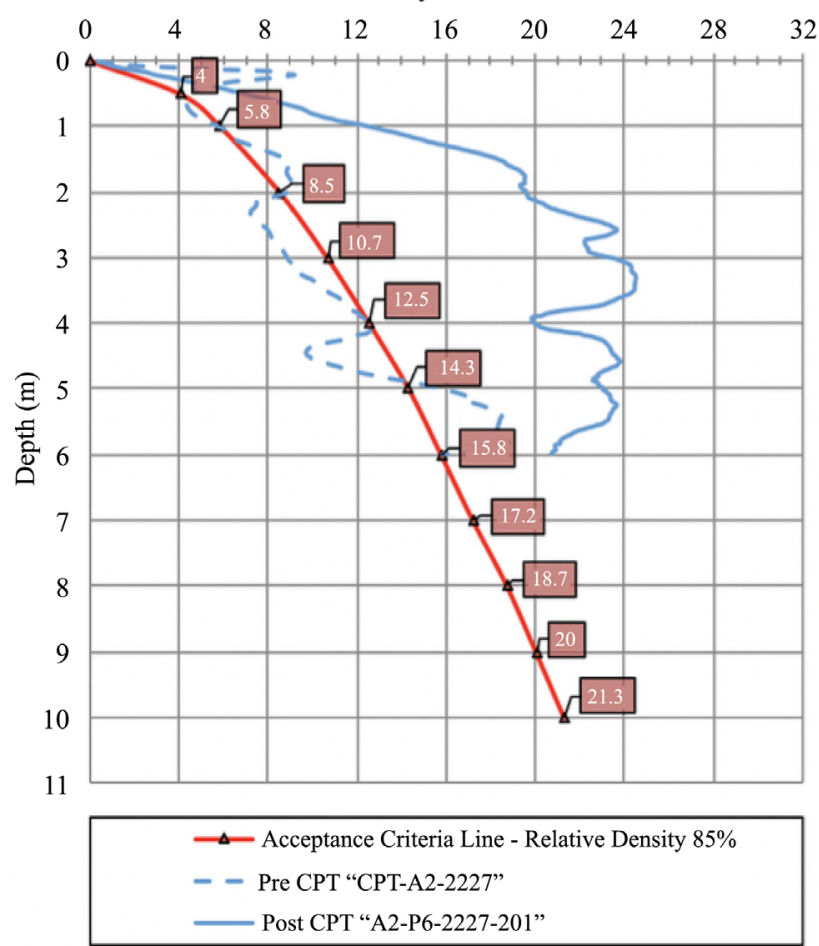

NGL

Subzone A2-P3-0734

$q_{\mathrm{c}}(\mathrm{MPa})$

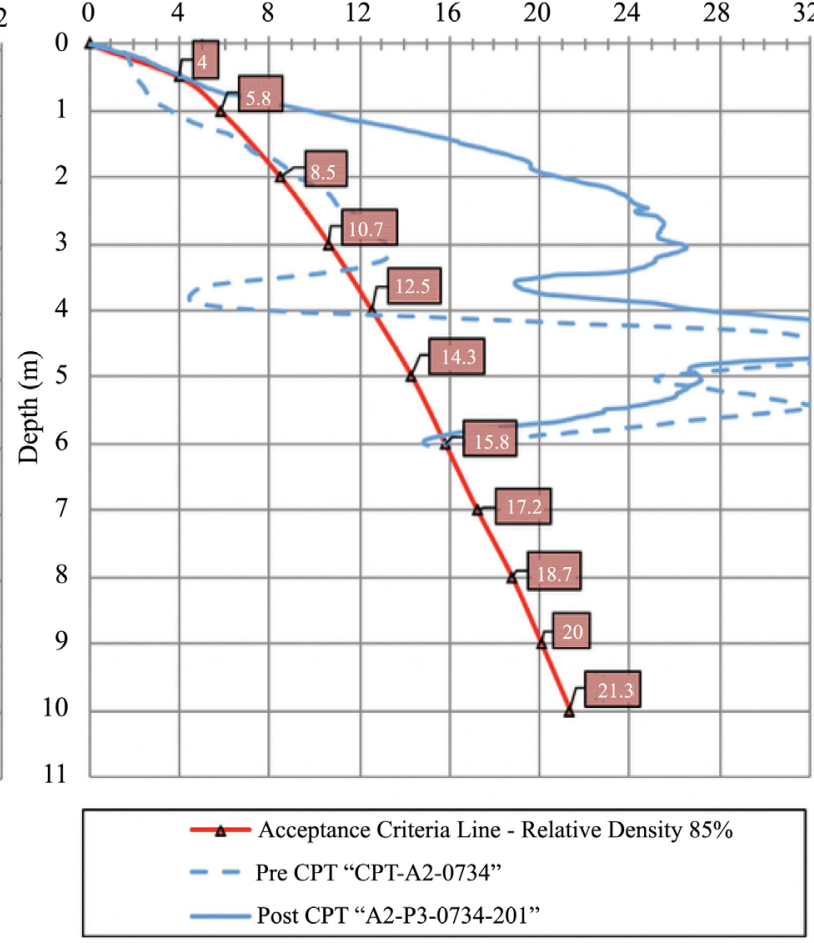

NGL

Subzone A2-P6-2331

$q_{c}(\mathrm{MPa})$

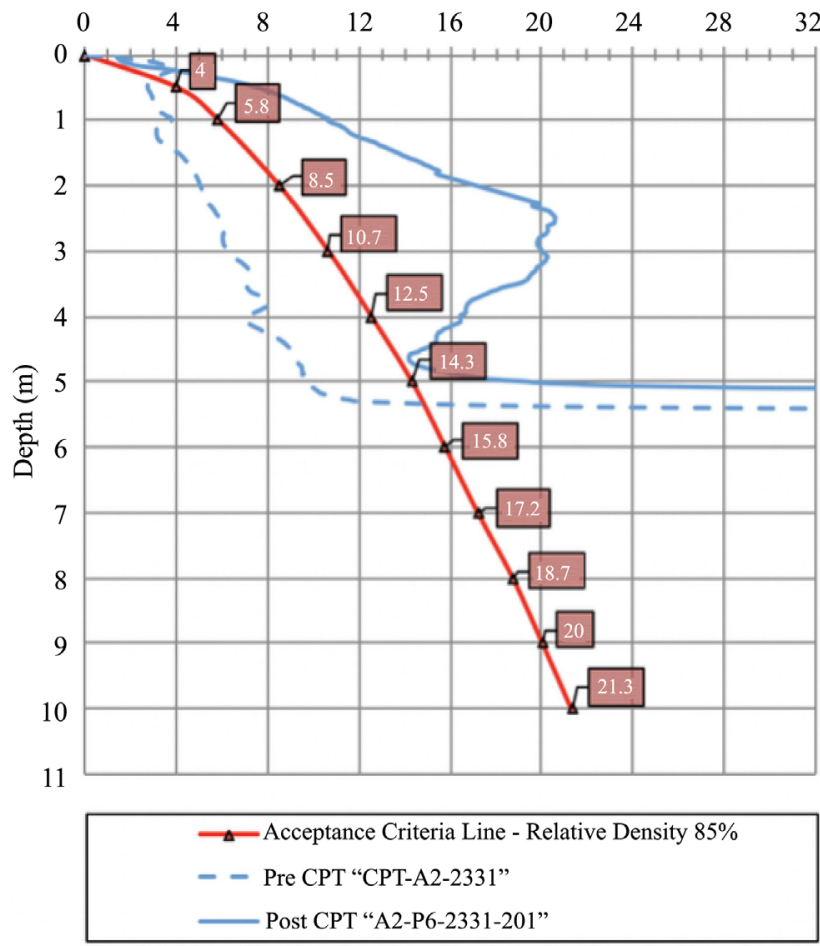

Figure 11. Natural soils, area 2, Subzone P3-0258, P3-0734, P6-2227, P6-2331. 


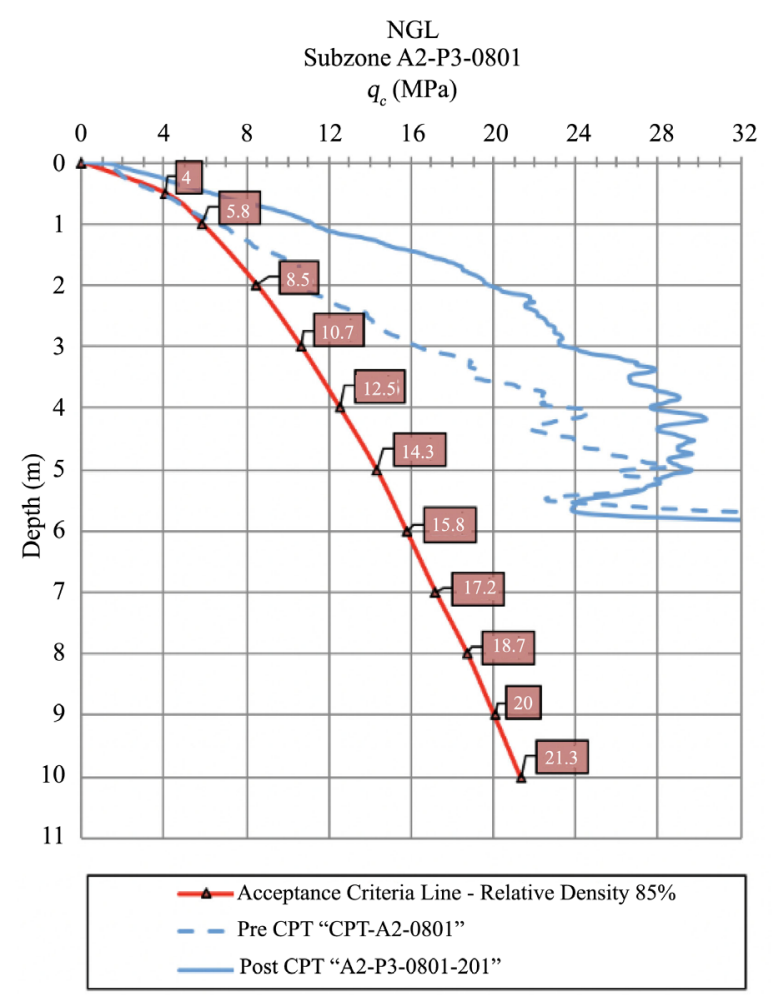

NGL

Subzone A2-P6-2484

$q_{c}(\mathrm{MPa})$

Figure 12. Natural Soils, area 2, Subzone P3-0801, P6-2484.

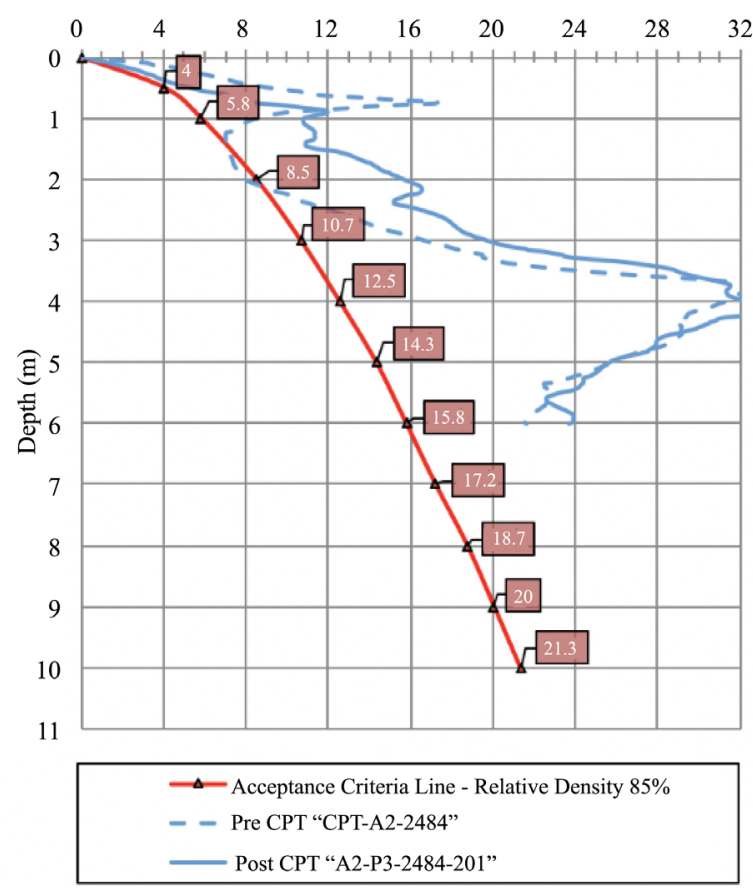

Figure 12. Natural Soils, area 2, Subzone P3-0801, P6-2484.

\section{$\underline{\text { Area A5 }}$}

NGL

Subzone A5-P1-0134

$q_{c}(\mathrm{MPa})$
NGL

Subzone A5-P1-0170

$q_{\mathrm{c}}(\mathrm{MPa})$

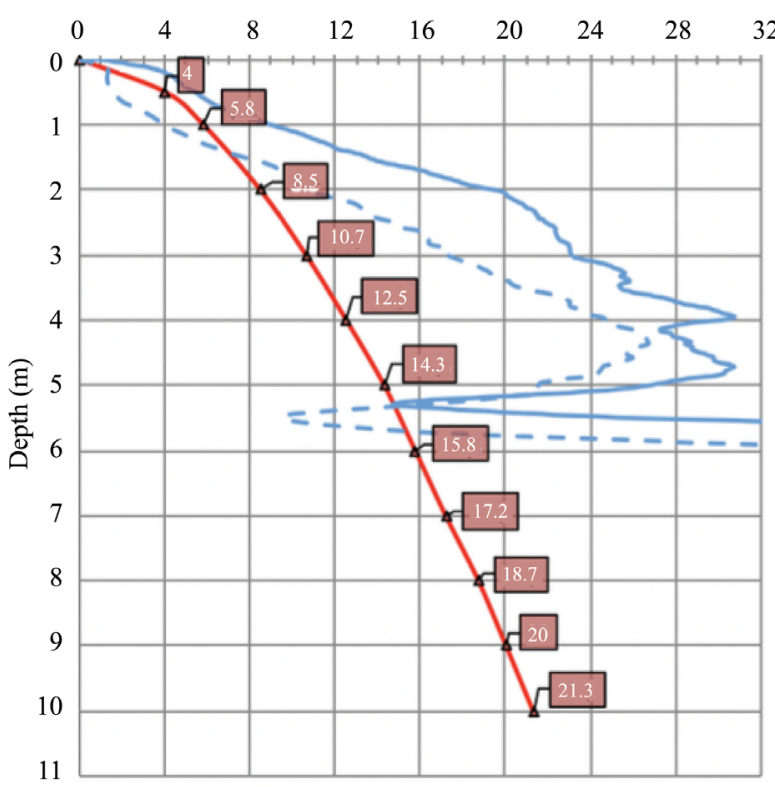

$\triangle$-Acceptance Criteria Line - Relative Density $85 \%$

- - Pre CPT "CPT-A5-0134"

— Post CPT "A5-P1-0134-201"

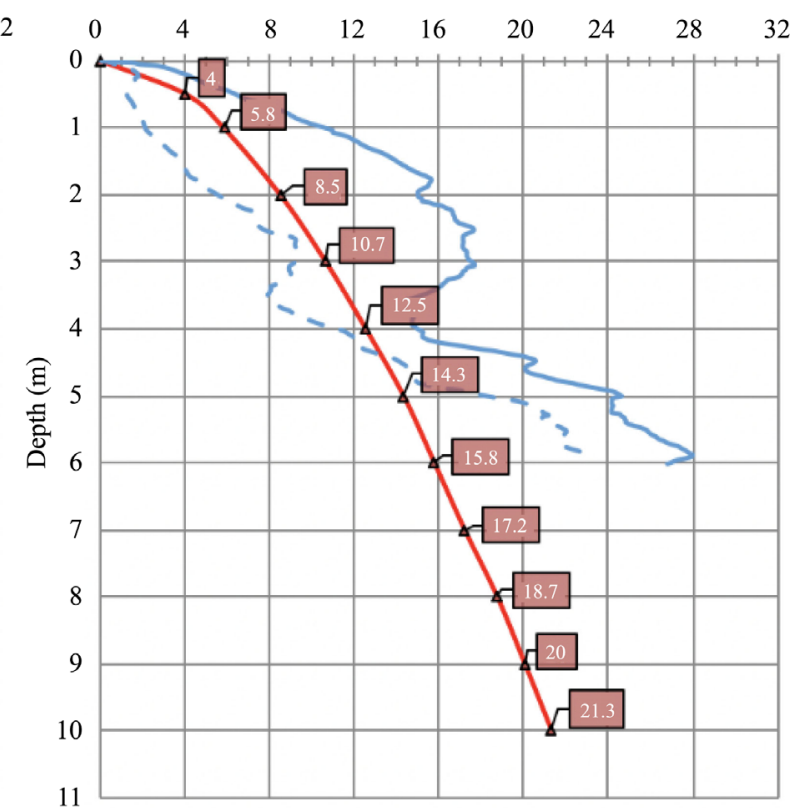

$\triangle$ Acceptance Criteria Line - Relative Density $85 \%$ - - Pre CPT "CPT-A5-0170" — Post CPT "A5-P1-0170-201" 
NGL

Subzone A5-P1-0255

$q_{\mathrm{c}}(\mathrm{MPa})$

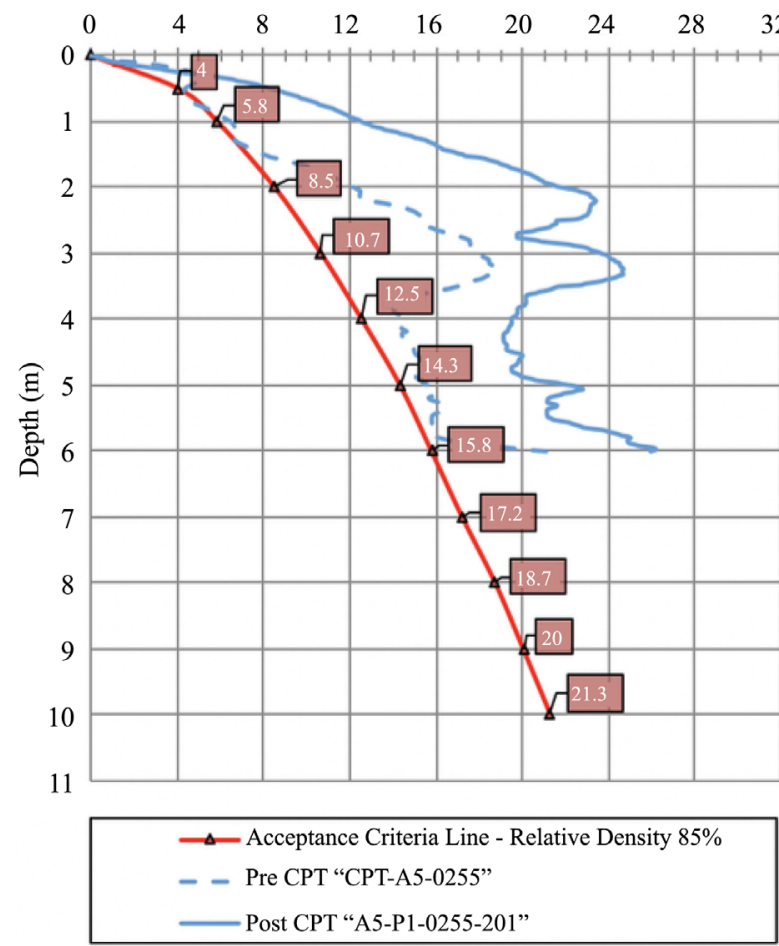

NGL

Subzone A5-P2-0268

$q_{c}(\mathrm{MPa})$

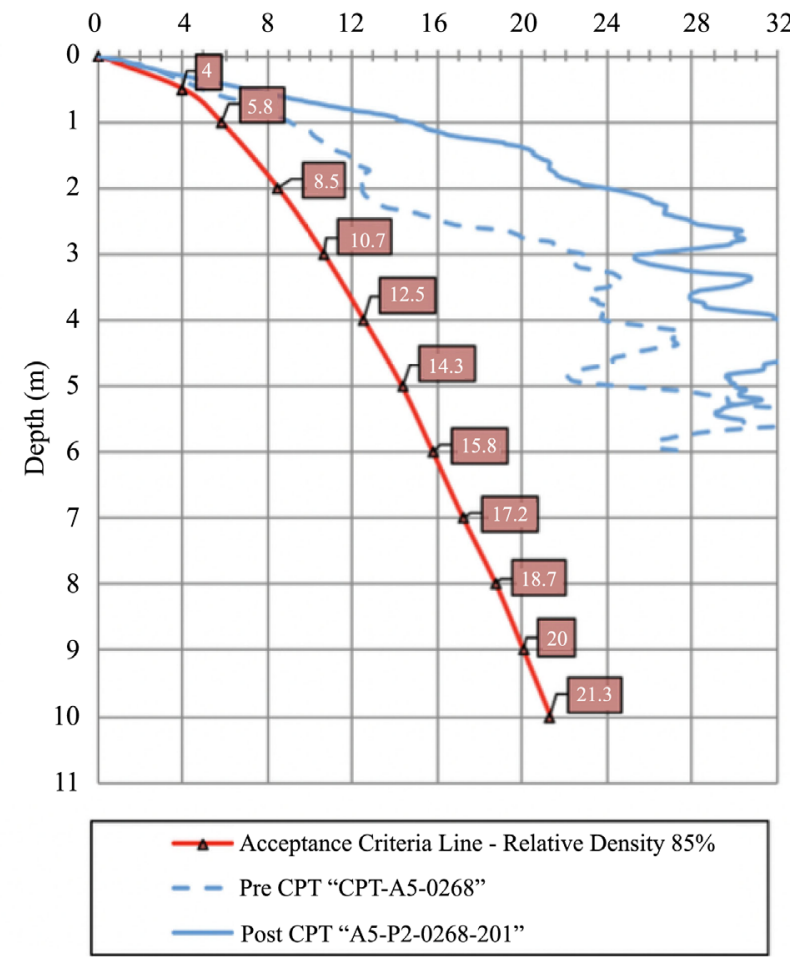

Figure 13. Natural soils, area 5, Subzone P1-0134, P1-0170, P1-0255, P2-0268.

NGL

Subzone A5-P1-0246

$q_{\mathrm{c}}(\mathrm{MPa})$

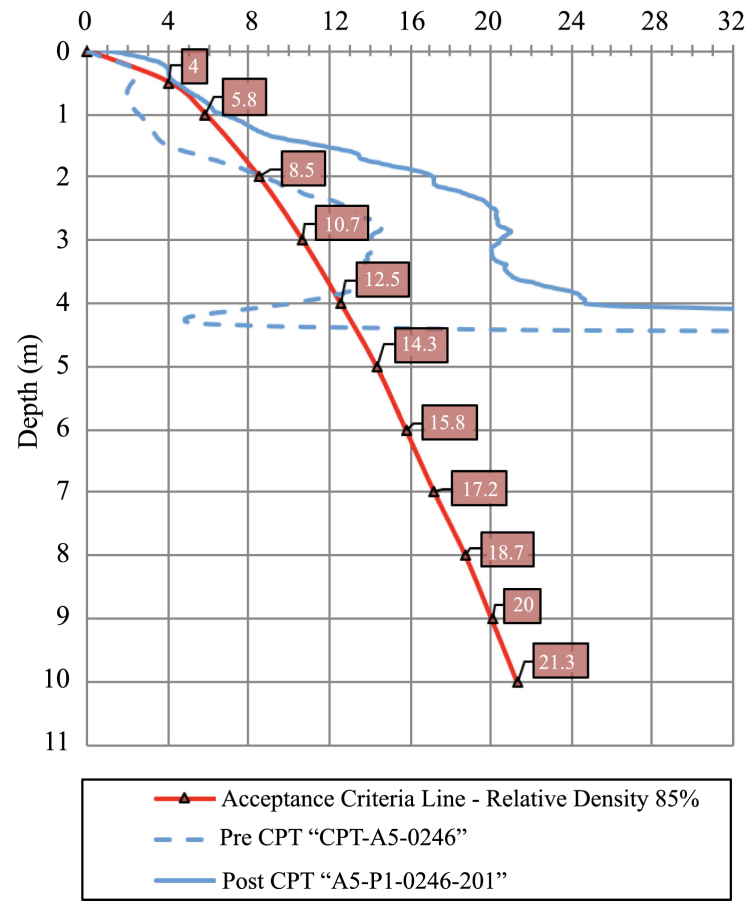

Figure 14. Natural soils, area 5, Subzone P1-0246. 


\subsection{Fill Soils $\left(3,300,000 \mathrm{~m}^{2}\right)$}

The soil improvement RIC performance parameters used for the compaction of the fill soils are provided below in Table 4.

Table 4. Details of production parameters applied on filling areas.

\begin{tabular}{|c|c|c|c|c|c|}
\hline \multicolumn{6}{|c|}{ Fill Soils $\left(3,300,000 \mathrm{~m}^{2}\right)$} \\
\hline \multicolumn{6}{|c|}{ Areas A1 \& A2 } \\
\hline \multicolumn{6}{|c|}{ Type of Grid: Square } \\
\hline \multicolumn{6}{|c|}{ Final grid: $3.5 \times 3.5 \mathrm{~m}$} \\
\hline Phase & Pass & Hammer Weight & Drop Height & Blows/Point & Foot Diameter \\
\hline 1 & 1 & 16 ton & $0.6 \mathrm{~m}$ & $10-15$ & $2.6 \mathrm{~m}$ \\
\hline 2 & 1 & 16 ton & $0.6 \mathrm{~m}$ & $10-15$ & $2.6 \mathrm{~m}$ \\
\hline 3 & 1 & 16 ton & $0.6 \mathrm{~m}$ & $10-15$ & $2.6 \mathrm{~m}$ \\
\hline
\end{tabular}

The CPTs performed in area A1 and A2 in fill soils prior and after compaction are shown in Figures 15-17 along with the acceptance criteria.

\section{Area A1}

Fill

Subzone A1-P1-0157

$q_{\mathrm{c}}(\mathrm{MPa})$

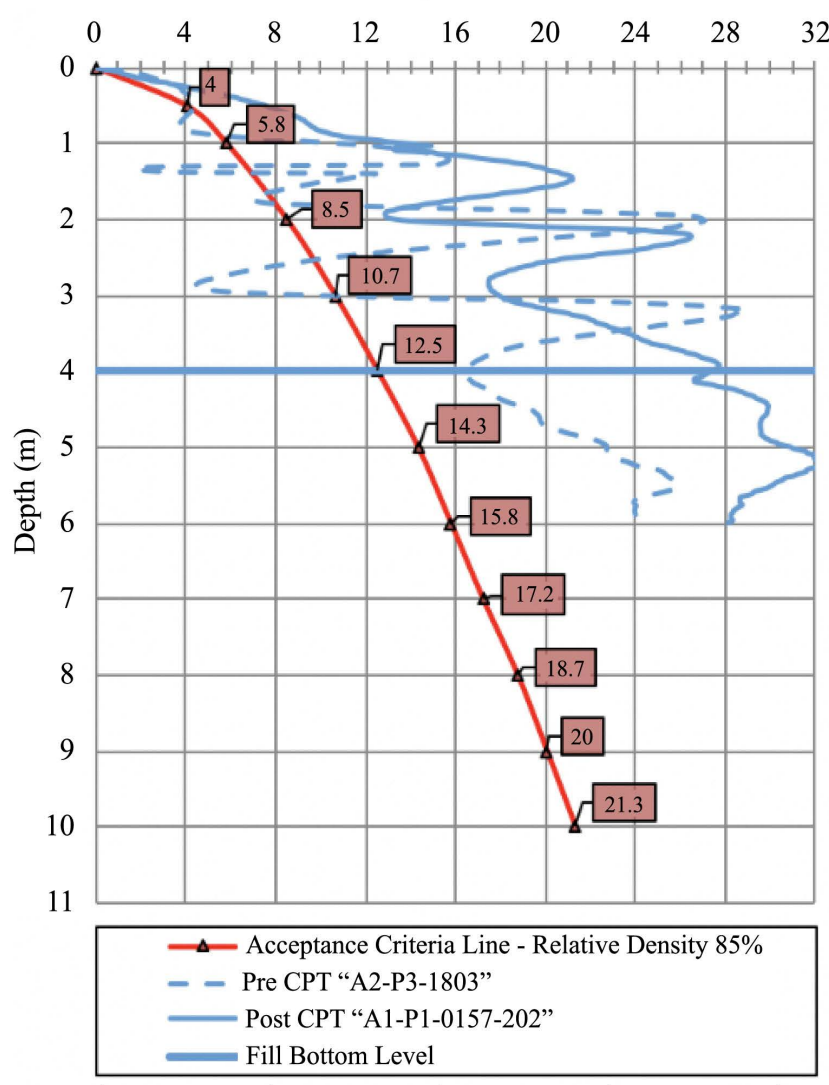

Fill

Subzone A1-P1-0206

$q_{\mathrm{c}}(\mathrm{MPa})$

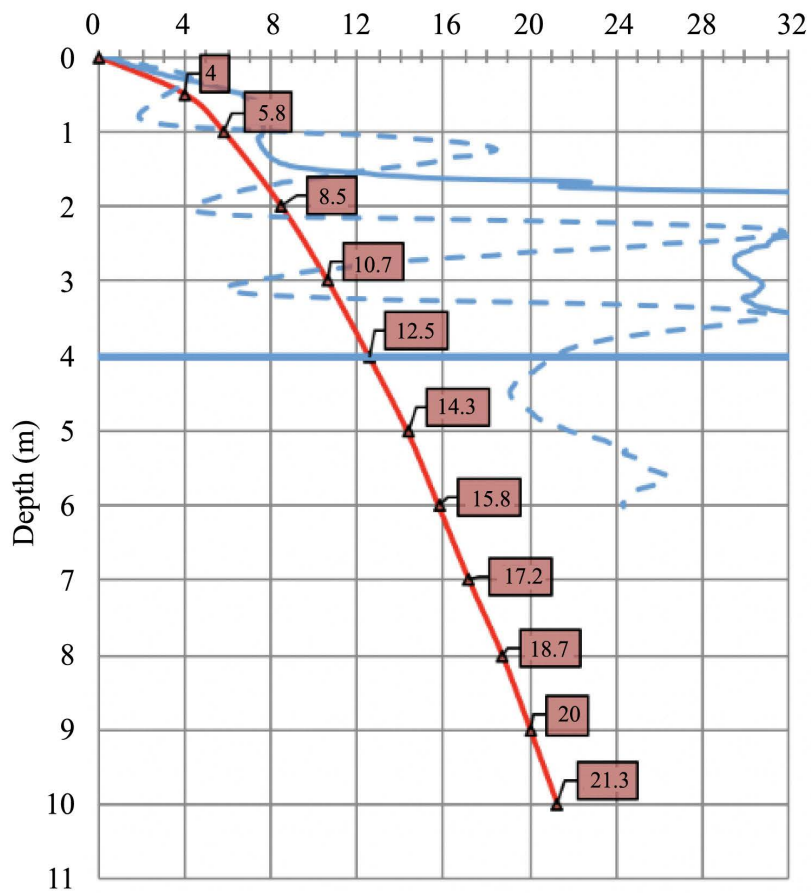

11

$\triangle$ Acceptance Criteria Line - Relative Density $85 \%$

- - Pre CPT “A2-P3-1804”

Post CPT “A1-P1-0206-202”

Fill Bottom Level 

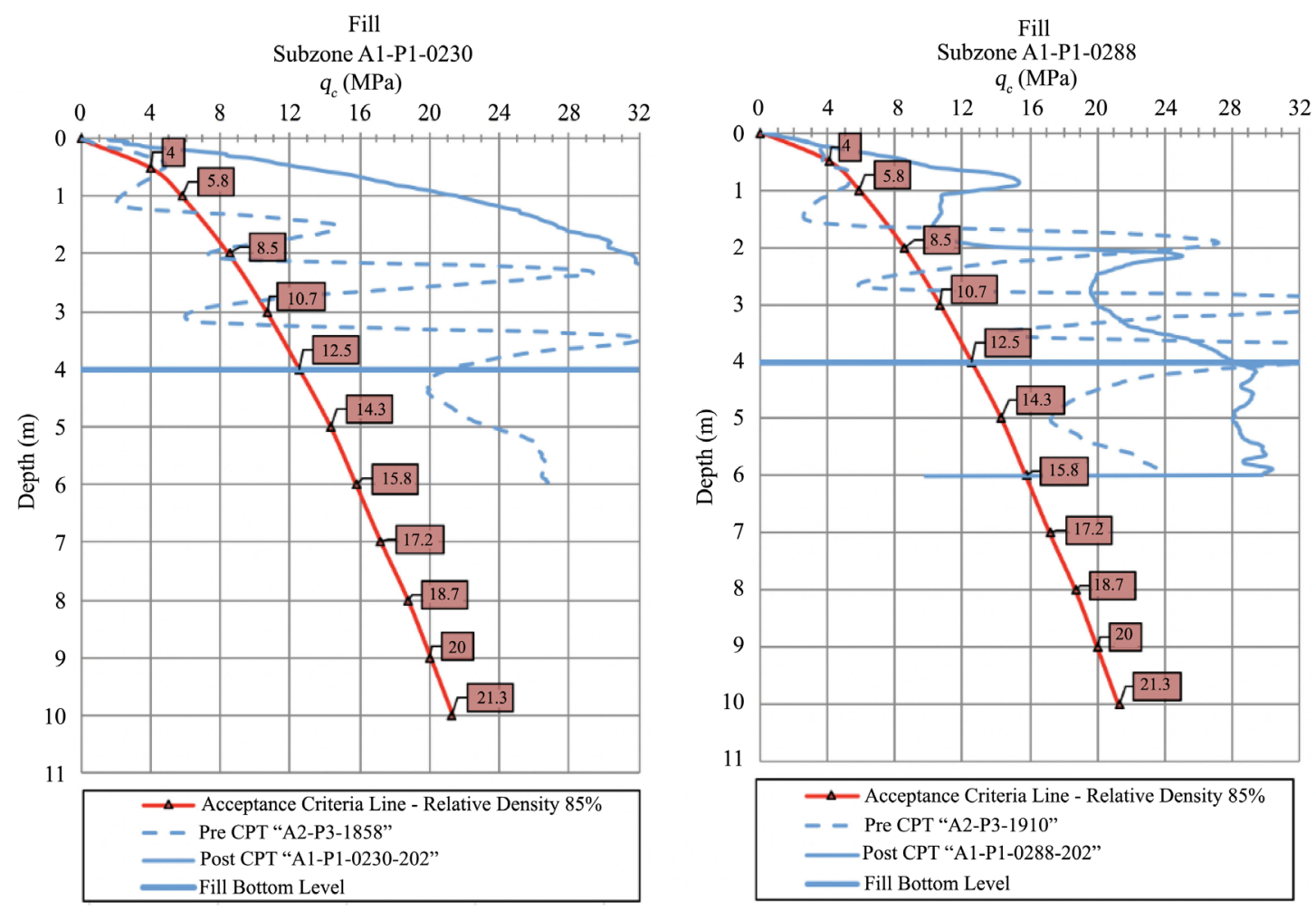

Figure 15. Fill soils, area 1, Subzone P1-0157, 0206, 0230, 0288.

\section{Area A2}

Fill

Subzone A2-P3-1804 $q_{\mathrm{c}}(\mathrm{MPa})$

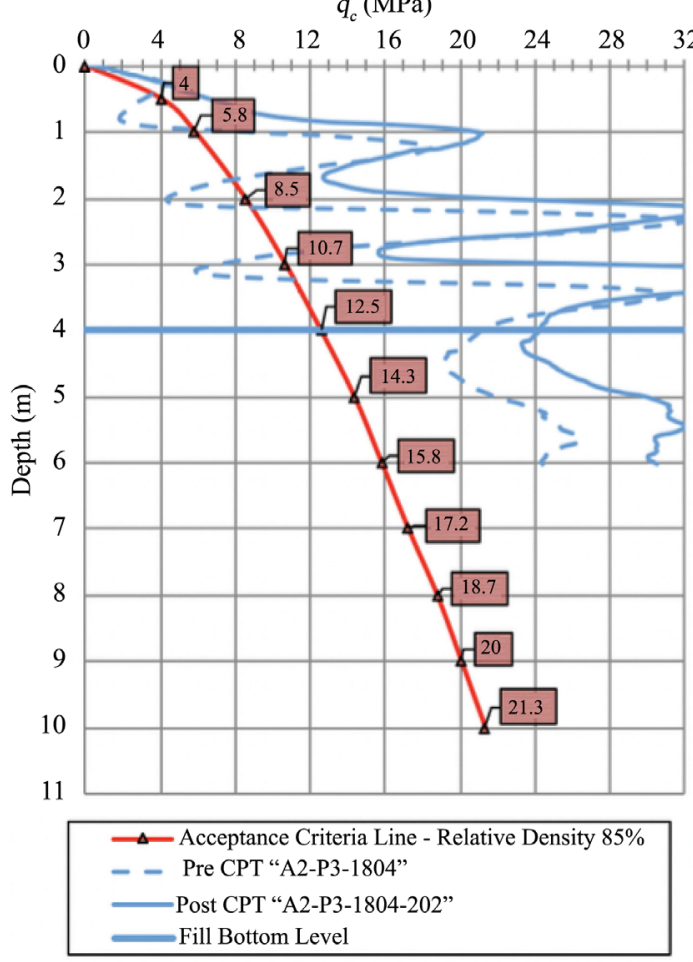

Fill

Subzone A2-P3-1858

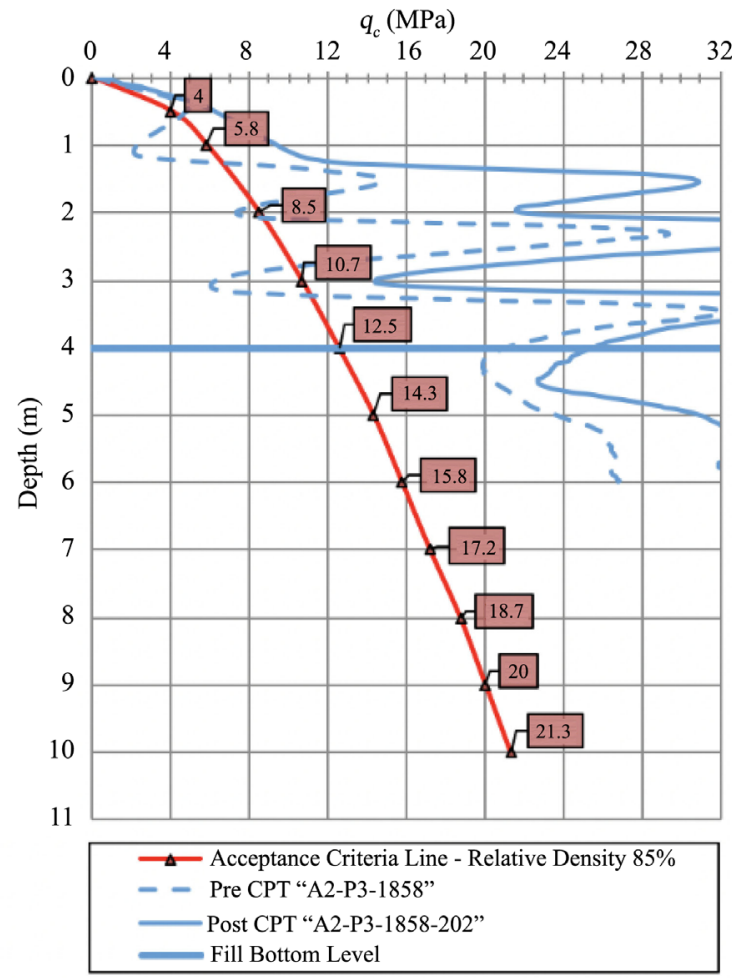


Fill

Subzone A2-P3-1910

$q_{\mathrm{c}}(\mathrm{MPa})$

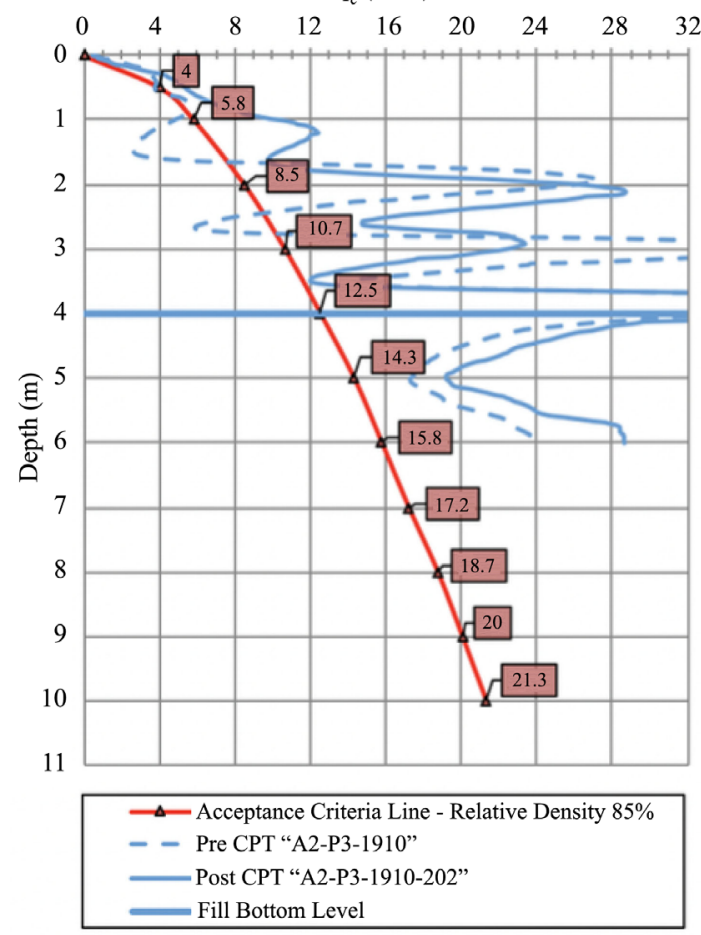

Figure 16. Fill soils, area 2, Subzone P3-1804, 1858, 1910.

Subzone A2-P2-1486 $q_{c}(\mathrm{MPa})$

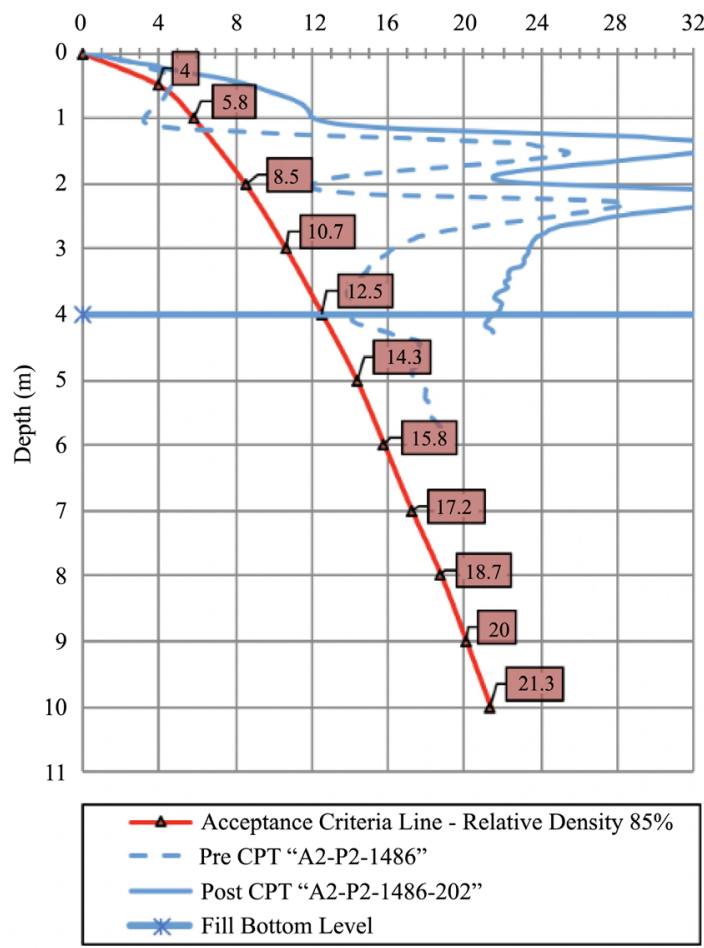

Fill

Subzone A2-P2-1538

$q_{\mathrm{c}}(\mathrm{MPa})$

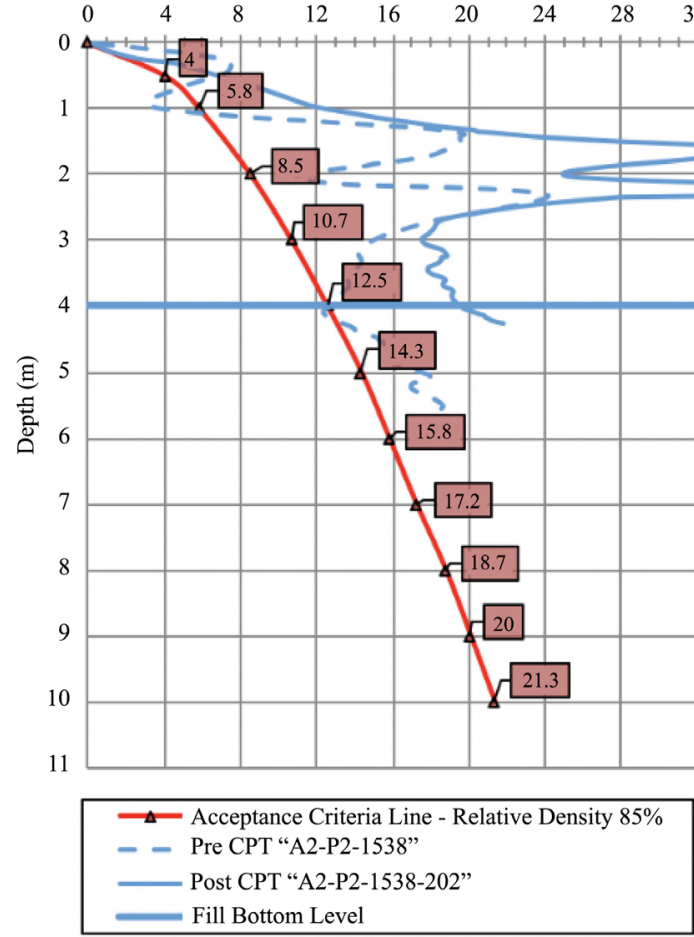

Figure 17. Fill soils, area 2, Subzone P2-1486, 1538. 


\section{Conclusions}

Ground improvement activities by means of RIC in an early site preparation contract were presented as a case study within this paper. The subject site is located approximately $20 \mathrm{~km}$ west of Tanajib, Saudi Arabia.

The total project area consists of nearly 6.3 million $\mathrm{m}^{2}$. The site preparation contract consists of cut and fill activities. Cutting operations range from 0 to $12.4 \mathrm{~m}$ (with an average of $6 \mathrm{~m}$ ), while filling thicknesses range from 0 to $8 \mathrm{~m}$ (with an average of $4 \mathrm{~m}$ ).

The RIC technique was used for improving the strength of fill materials of substantial thickness (up to $4 \mathrm{~m}$ ) on a single action from the top surface as an alternative to the conventional technique conducted by rollers. Furthermore, RIC was a favorable substitute for the natural loose soil excavation and re-compaction (at layers) when considering cost and time schedule effectiveness. The objective of the soil treatment scheme is to increase the relative density of the soils (both fill and natural) to $85 \%$.

Post soil treatment results showed a considerable increase of the cone resistance as compared to the results of tests prior of any compaction, whereas the project's specification criterion of $85 \%$ of relative density was achieved across the entire site preparation area for both the natural and fill soils with thicknesses of compliance at least $5 \mathrm{~m}$ from the surface where RIC was been executed.

\section{Conflicts of Interest}

The authors declare no conflicts of interest regarding the publication of this paper.

\section{References}

[1] Watts, K.S. and Charles, J.A. (1993) Initial Assessment of a New Rapid Impact Ground Compactor. Proceedings of the Conference on Engineered Fills, London.

[2] Allen, S. (1996) The Low Energy Dynamic Compaction of Soil. Ph.D. Dissertation, University of Wales, Cardiff.

[3] Kristiansen, H. and Davies, M. (2004) Ground Improvement Using Rapid Impact Compaction. 13th World Conference on Earthquake Engineering, Vancouver.

[4] Tara, D. and Wilson, P. (2004) Rapid Impact Compactor Ground Improvement, Vibration Monitoring and Densification Assessment. Report Submitted to Rapid Impact Compactors Ltd., Thurber Engineering Ltd., Delta, BC.

[5] Synac, O. and Serridge, C.J. (2006) Application of the Rapid Impact Compaction (RIC) Technique for Risk Mitigation in Problematic Soils. In The 10 th IAEG International Congress, Nottingham, 1-13.

[6] Simpson, L.A., Jang, S.T., Ronan, C.E. and Splitter, L.M. (2008) Liquefaction Potential Mitigation Using Rapid Impact Compaction. Proceedings of the 4th Conference of Geotechnical Earthquake Engineering and Soil Dynamics, Sacramento, CA, May. https://doi.org/10.1061/40975(318)110

[7] Becker, P.J. (2011) Assessment of Rapid Impact Compaction for Transportation Infrastructure Applications. Graduate Thesis, Iowa State University, Ames, IA.

[8] Vukadin, V. (2013) The Improvement of the Loosely Deposited Sands and Silts with 
the Rapid Impact Compaction Technique on Brežice Test Sites. Engineering Geology, 160, 69-80. https://doi.org/10.1016/j.enggeo.2013.03.025

[9] Ghassemi, A., Pak, A. and Shahir, H. (2009) Numerical Study of the Coupled Hydro-Mechanical Effects in Dynamic Compaction of Saturated Granular Soils. ComputatioComputers and Geotechnics, 37, 10-24.

https://doi.org/10.1016/j.compgeo.2009.06.009

[10] Falkner, F.J., Adam, C., Paulmichl, I., Adam, D. and Fürpass, J. (2010) Rapid Impact Compaction for Middle-Deep Improvement of the Ground-Numerical and Experimental Investigations. 14 $4^{\text {th }}$ Danube-European Conference on Geotechnical Engineering, Bratislava, June.

[11] Baldi, G., Bellotti, V.N., Ghionna, N., Jamiolkowski, M. and Pasqualini, E. (1986) Interpretation of CPT's and CPTU's-2nd Part: Drained Penetration of Sands. Proceedings of the 4th International Geotechnical Seminar Field Instrumentation and In-Situ Measurements, Nanyang Technological Institute, Singapore, 25-27 November 1986, 143-156.

[12] Jamiolkowski, M., Baldi, G., Belloti, R., Ghionna, V. and Pasqualini, E. (1985) Penetration Resistance and Liquefaction of Sands. Proceedings of the Eleventh International Conference on Soil Mechanics and Foundation Engineering, San Francisco.

[13] Schmertmann, J.H. (1978) Guidelines for Cone Penetration Test, Performance and Design. Report FHWA-TS-78-209, Federal Highway Administration, Washington DC, 78-209. 